\title{
Development and Techno-economic Analyses of a Novel Hydrogen Production Process via Chemical Looping
}

\author{
Husain Bahzad $^{\mathrm{a}}$, Nilay Shah ${ }^{\mathrm{a}}$, Niall Mac Dowell ${ }^{\mathrm{b}}$, Matthew Boot-Handford ${ }^{\mathrm{a}}$, Salman \\ Masoudi Soltani ${ }^{c, d}$, Minh Ho Ho $^{\mathrm{e}}$ and Paul S. Fennell ${ }^{\mathrm{a}, *}$ \\ aDepartment of Chemical Engineering, Imperial College of London, SW7 2AZ London, UK \\ ${ }^{\mathrm{b}}$ Centre for Environmental Policy, Imperial College of London, SW7 1NA London, UK \\ 'Department of Chemical Engineering, College of Engineering, Design and Physical Sciences, Brunel \\ University London, UB8 3PH London, UK

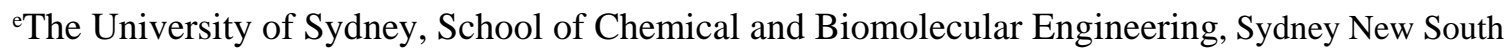 \\ Wales 2006, Australia \\ Corresponding Author’s Tel: +44 (0)20 7594 6637; Email: p.fennell@imperial.ac.uk
}

\begin{abstract}
In this work, a novel hydrogen production process (Integrated Chemical Looping Water Splitting "ICLWS") has been developed. The modelled process has been optimized via heat integration between the main process units. The effects of the key process variables (i.e. the oxygen carrier-to-fuel ratio, steam flow rate and discharged gas temperature) on the behaviour of the reducer and oxidiser reactors were investigated. The thermal and exergy efficiencies of the process were studied and compared against a conventional steammethane reforming (SMR) process. The process economic feasibility was finally evaluated by evaluating the corresponding CAPEX, OPEX and the first-year plant cost per kg of the hydrogen produced. The results show that the thermal efficiency of the ICLWS process is improved by 31.1\% compared to the baseline (Chemical Looping Water Splitting without heat integration) process. Also, the hydrogen efficiency and the effective efficiencies were higher by $11.7 \%$ and $11.9 \%$, respectively compared to the SMR process. The sensitivity analysis showed that the oxygen carrier-to-methane and -steam ratio can impact the discharged gas and solid conversions from both the reducer and oxidiser. Also, unlike for the oxidiser, the temperature of the discharged gas and solids from the reducer had an impact on the gas and solid conversion. The economic evaluation of the process showed hydrogen production costs of \$1.41 and \$1.62 per kilogram of hydrogen produced for $\mathrm{ZrO}_{2}$ and $\mathrm{MgAl}_{2} \mathrm{O}_{4}$ as support materials, respectively. This value was $14 \%$ and $1.2 \%$ lower for the SMR process with $\mathrm{MgAl}_{2} \mathrm{O}_{4}$ and $\mathrm{ZrO}_{2}$ as support material, respectively.
\end{abstract}

Keywords: Chemical Looping, Hydrogen Production, Techno-Economic Evaluation, Heat Integration, Sensitivity Analysis. 


\section{Introduction}

Hydrogen is used as transportation fuel, for the production of ammonia, and in fuels cells, the pharmaceutical and food industries, and petroleum refining e.g. in hydro-treating and hydrocracking units [1-3]. With steam being the only combustion product, hydrogen is considered as an environmentally-benign (at point of use) energy vector. Hydrogen is currently mainly produced via the steam methane reforming "SMR" process [2, 4, 5]releasing $\mathrm{CO}_{2}$, one of the major greenhouse gases responsible for global warming $[4,6]$. Climate change and resource depletion means that it will be necessary to rethink many existing processes, to avoid emission of $\mathrm{CO}_{2}$ to the atmosphere and to improve overall energy utilisation whilst doing so. SMR has been the main industrial pathway to $\mathrm{H}_{2}$ production due to its economic attractiveness; the first year cost associated with the SMR process is $2.31 \$ / \mathrm{kg} \mathrm{H}_{2}$ produced [4] i.e. the lowest among current alternative $\mathrm{H}_{2}$ production processes. The thermal efficiency of a typical SMR process is 68-70\% [6, 7]. In this process, methane is reacted with steam in a reformer to produce syngas [8]:

$$
\begin{array}{ll}
\mathrm{CH}_{4}+\mathrm{H}_{2} \mathrm{O}=\mathrm{CO}+3 \mathrm{H}_{2} & \Delta \mathrm{H}_{298 \mathrm{~K}}=205 \mathrm{~kJ} / \mathrm{mol} \\
\mathrm{CH}_{4}+2 \mathrm{H}_{2} \mathrm{O}=\mathrm{CO}_{2}+4 \mathrm{H}_{2} & \Delta \mathrm{H}_{298 \mathrm{~K}}=165 \mathrm{~kJ} / \mathrm{mol}
\end{array}
$$

In order to achieve a higher $\mathrm{H}_{2}$-to-CO ratio, the syngas goes through several process units including a water-gas shift reactor, followed by a separation unit e.g. a pressure-swing adsorption (PSA) column or a Pd-membrane module $[4,9]$. An acid gas removal stage is a requisite for the subsequent $\mathrm{CO}_{2}$ capture unit. These processes are energy intensive and thus result in a drop in the thermal efficiency of the SMR process $[2,6]$.

Due to its simplicity and the inherent $\mathrm{CO}_{2}$ capture, chemical looping is a promising technology that can be also utilised for hydrogen production in-situ with $\mathrm{CO}_{2}$ capture [10, $11]$.

Chemical looping reforming and chemical looping water splitting are technologies proposed for hydrogen production with $\mathrm{CO}_{2}$ capture [3, 11, 12]. Chemical looping reforming (CLR) is a technology where the oxygen required for the fuel combustion is supplied by an oxygen carrier instead of air, preventing contact between the air and the fuel [13]. Chemical looping reforming is classified into three categories: i), chemical looping reforming for syngas (CLR(a)) ii) Chemical looping reforming integrated with 
oxidation for hydrogen and syngas (CLR(w)) and iii) steam reforming integrated with chemical looping (CLRS) as shown in Fig.1 [12, 14]. CLR(a) is the basic form of the CLR process, where partial oxidation and reforming of the fuel takes place, producing a gas mixture mainly comprised of $\mathrm{H}_{2} \mathrm{CO}$ and $\mathrm{CO}_{2}$. To obtain a high purity $\mathrm{H}_{2}$ stream, a WGS reactor followed by a PSA process is necessary. The reduced oxygen carrier is then regenerated in the air reactor using air, as indicated in Fig.1(b) [12]. In CLR(w) syngas is produced in the fuel reactor similar to CLR(a). However, unlike CLR(a), the reduced oxygen carrier from the fuel reactor is partially oxidised in a steam reactor producing a pure hydrogen stream that can be easily extracted by condensing the steam. Finally, the oxygen carriers are fully regenerated in the air reactor. For CLRS the reactions in the steam reformer do not differ from the conventional SMR process, however the reformer product gas is used as the fuel for the fuel reactor. The heat for the steam methane reforming reactions is supplied from the hot oxygen carriers circulated from the air reactor. The main advantages of the CLR process as opposed to SMR are: 1) No external source of heat needed for the reformer; 2) No emissions of $\mathrm{CO}_{2}$ from external combustion source; 3) Less catalyst and steam required per unit fuel fed; 4) High reaction rate since no limitations are imposed by heat transfer [15]. However, CLR processes still require WGS and separations units such as PSA to achieve a high purity $\mathrm{H}_{2}$ product, which increases the CAPEX of the process [12]. Several studies have been conducted on ideal oxygen carriers for the CLR process. For CLR(a) Ni-based oxygen carriers were recommended [16], though toxicity may be an issue. In addition, a number of works have been performed to investigate reaction rate kinetics, thermodynamic properties of the oxygen carrier, the main parameters affecting the $\mathrm{H}_{2}$ production rate and process performance and feasibility, which are summarised in the literature [12, 14]. Furthermore, the CLRS process has been modified by adding a sorbent to 'break' the WGS equilibrium limitations and reduce the reforming temperature to achieve high $\mathrm{H}_{2}$ yield in addition to $\mathrm{CO}_{2}$ capture. This sorbent-enhanced method (SE-CLSR) lowers the energy penalty of CLRS as well as the process CAPEX since fewer separating units are required to produce a high purity $\mathrm{H}_{2}$ product with in-situ with $\mathrm{CO}_{2}$ capture [17]. In addition to the reforming and WGS reactions (Eqs 1 and 2) the sorption reaction is represented as follows [14]:

$\mathrm{MeO}+\mathrm{CO}_{2}=\mathrm{MeCO}_{3}\left(\mathrm{Me}: \mathrm{CaO}, \mathrm{Li}_{2} \mathrm{ZrO}_{3}\right)$ 
SE-CLSR has also been tested for liquid fuel (ethanol), showing high hydrogen selectivity with low energy demand [18].

Chemical looping water splitting (CLWS) is an alternative approach, producing $\mathrm{H}_{2}$ and $\mathrm{CO}_{2}[12,19]$. In this process, the separation process for $\mathrm{CO}_{2}$ is simply a steam condenser $[7,20,21]$ As a result, the corresponding energy penalty is low. The thermal efficiency of the CLWS process is higher than that for SMR [2, 7, 21]. CLWS utilises a reducer, an oxidiser and an air reactor. In the reducer, the oxygen carrier (e.g. a metal oxide) is reduced, providing the oxygen required to combust the fuel and, thereby producing steam and carbon dioxide. In the oxidiser, the reduced metal oxide is partially oxidized by steam to produce $\mathrm{H}_{2}$. Finally, the partially-oxidised metal oxide is regenerated via full oxidation with air in a third "air" reactor [3, 7, 21]. A schematic diagram of a three-reactor CLWS process is shown in Fig. 2. A number of studies have been done, modelling CLWS with gaseous [5] (syngas chemical looping process (SCL) integrated with gas turbines for power generation), [7, 19] (iron oxide chemical looping with natural gas fuel), [21] (iron oxide chemical looping in three moving bed reactors with natural gas fuel together with a study of oxygen carrier selection), [22] (iron oxide chemical looping integrated with combined cycle power generation using natural gas or syngas), [23-25] (chemical looping with iron oxide oxygen carrier integrated with combined cycle using natural gas fuel). Additionally, solid fuels have been tested [9] (coal direct chemical looping (CDLC) for $\mathrm{H}_{2}$ and power production using an iron oxide oxygen carrier), [26] (iron oxide chemical looping using biomass (sawdust) and coal fuel coupled with combined cycle for power generation), [27] (comparison between the SCL and CDCL using iron oxide oxygen carrier), [28] (iron oxide chemical looping of biomass integrated with other chemical looping combustion process which uses $\mathrm{Cu}$ based oxygen carrier, also calcium oxide looping of biomass is proposed), [29] (iron oxide chemical looping with brown coal fuel integrated with the power cycle), [30] (SCL with black liquor fuel using iron oxide), [31] (CDCL with Fe and Cu bi- metallic oxygen carrier) and liquid fuels [32]. These studies have focused on process modelling and thermodynamic evaluation, including the overall thermal efficiency, and understanding the variables impacting the gas and solid conversions, together with the overall product efficiencies [2, 7, 19, 23, 25, 27, 31, 32]. These studies indicate that the hydrogen 
efficiency for the CLWS process using a gaseous feedstock ranges from between $71.3 \%$ [25] to $80.3 \%$ [23], while the highest overall process efficiency was $80.2 \%$ [23]. For CLWS with solid fuels, the hydrogen efficiency values were $65.3 \%$ [26] - 72\%[9]; the overall process efficiency for some recent studies achieves $90.3 \%$ at high operating pressure utilising a combined power generation cycle [29]. However, little is known about the techno-economic aspects and feasibility of the CLWS process [25, 26]. Also, there is a knowledge gap in the process heat integration potential with natural gas and a steam generation cycle (SGC) for power production [7, 23].

According to the brief comparison mentioned above between the CLR and CLWS processes, CLWS has a potential advantage over CLR owing to its higher overall process efficiency and simplicity. Therefore a CLWS process has been developed and simulated here using Aspen Plus V8.8. The energy efficiency of the process - coupled with power generation - was then optimized via heat integration. The optimized process was finally investigated for its techno-economic commercial viability.

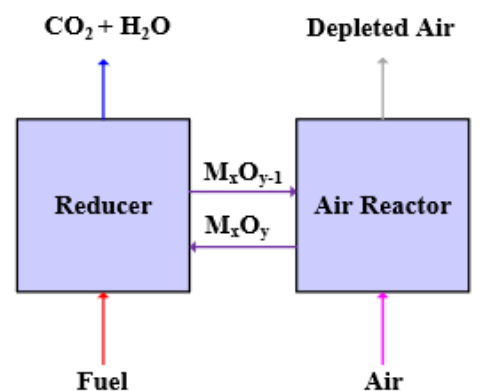

(a)

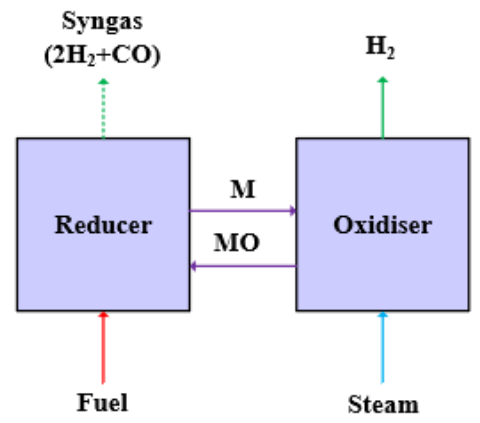

(c)

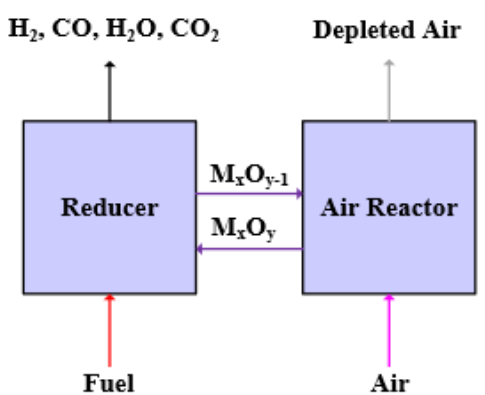

(b)

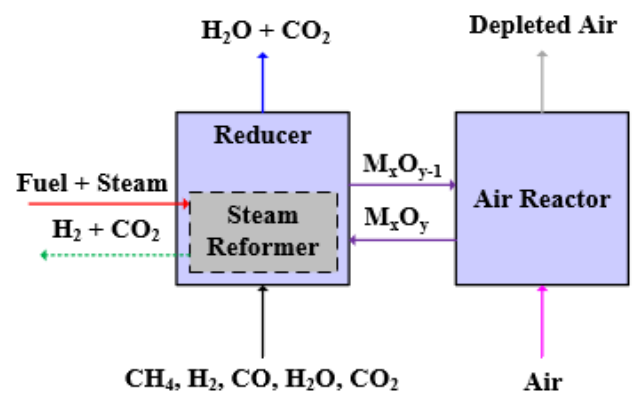

(d)

Fig.1: Chemical looping processes: (a) CLC; (b) CLR(a); CLR(w); CLSR [14] 


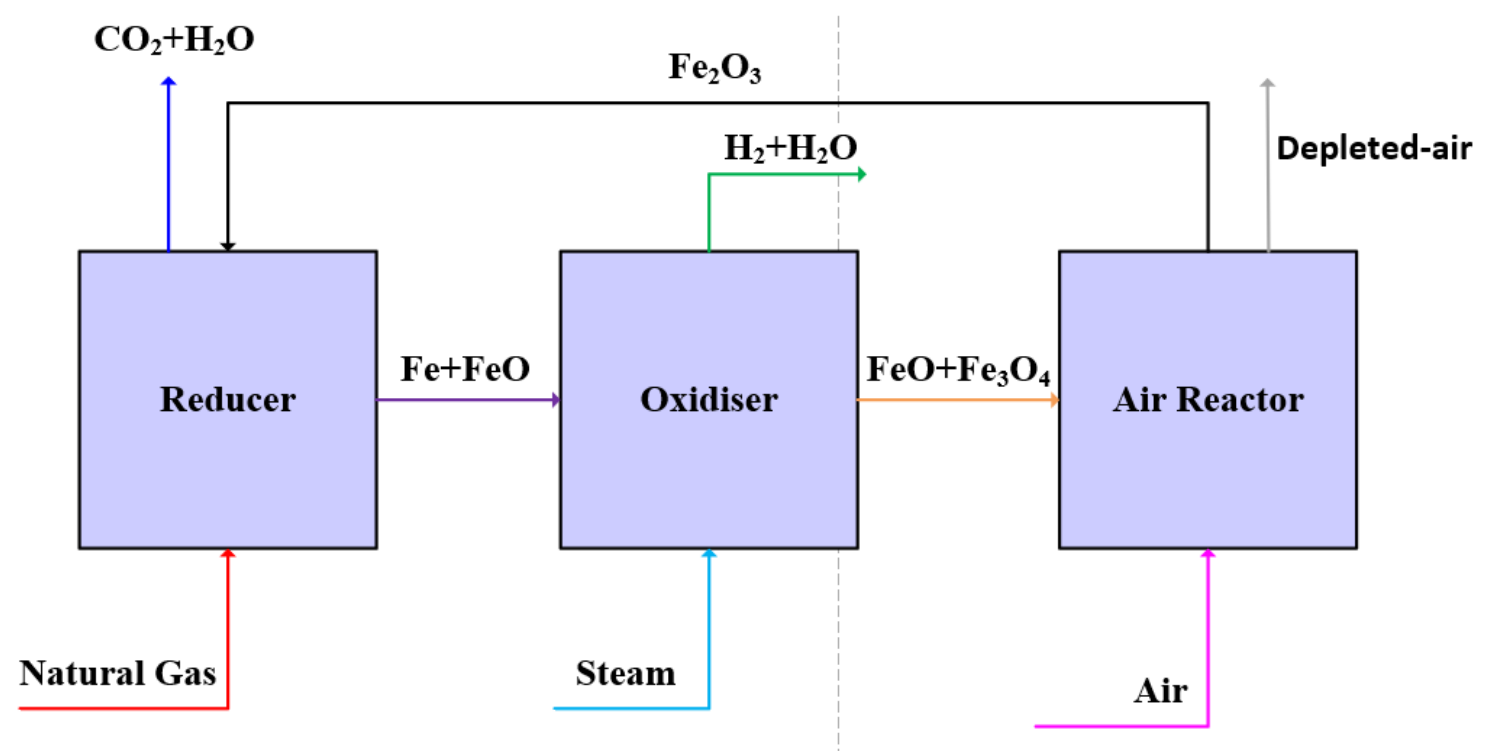

Fig.2: Schematic Diagram of CLWS Process

\section{Baseline Chemical Looping Water Splitting (BCLWS) Process}

\subsection{Thermodynamic Analyses}

The core reactions involved in the three CLWS reactors are shown in Table 1 [19].

Thermodynamic considerations indicate that three oxygen carriers can be used to produce $\mathrm{H}_{2}$ and capture $\mathrm{CO}_{2}$ within the same process [21, 33-35]. These three metal oxides (i.e. Fe, Co, W) can withstand the high temperatures throughout the CLWS process as a result of their high melting points (Table 2) [21]. In this study, the potential for an Fe-based carrier has been analysed.

In order for the oxygen carriers to maintain their activity throughout the redox cycles i.e. minimizing the attrition and agglomeration, the active metals must be mounted on an appropriate support [3, 21, 33]. A support material should also have a high heat capacity to store heat from the air reactor and transport it to the reducer [21, 33]. It also needs to be chemically stable with the associated active metal. Among various candidates, $\mathrm{ZrO}_{2}$ and $\mathrm{MgAl}_{2} \mathrm{O}_{4}$ have showed high thermal and chemical stabilities when tested with $\mathrm{Fe}_{2} \mathrm{O}_{3}$-based oxygen carriers [21]. 
Table 1: Main reactions in the CLWS process [19]

\section{Reactor}

Reducer

Oxidiser

Air reactor
Main reactions taking place

(4) $6 \mathrm{Fe}_{2} \mathrm{O}_{3}+2 \mathrm{CH}_{4} \longleftrightarrow 4 \mathrm{Fe}_{3} \mathrm{O}_{4}+2 \mathrm{CO}+4 \mathrm{H}_{2}$

(5) $2 \mathrm{Fe}_{3} \mathrm{O}_{4}+2 \mathrm{CH}_{4} \longleftrightarrow 6 \mathrm{FeO}+2 \mathrm{CO}+4 \mathrm{H}_{2}$

(6) $2 \mathrm{FeO}+2 \mathrm{CH}_{4} \longleftrightarrow 2 \mathrm{Fe}+2 \mathrm{CO}+4 \mathrm{H}_{2}$

(7) $6 \mathrm{Fe}_{2} \mathrm{O}_{3}+2 \mathrm{CO} / 2 \mathrm{H}_{2} \longleftrightarrow 4 \mathrm{Fe}_{3} \mathrm{O}_{4}+2 \mathrm{CO}_{2} / 2 \mathrm{H}_{2} \mathrm{O}$

(8) $\quad 2 \mathrm{Fe}_{3} \mathrm{O}_{4}+2 \mathrm{CO} / 2 \mathrm{H}_{2} \longleftrightarrow 6 \mathrm{FeO}+2 \mathrm{CO}_{2} / 2 \mathrm{H}_{2} \mathrm{O}$

(9) $\quad 2 \mathrm{FeO}+2 \mathrm{CO} / 2 \mathrm{H}_{2} \longleftrightarrow 2 \mathrm{Fe}+2 \mathrm{CO}_{2} / 2 \mathrm{H}_{2} \mathrm{O}$

(10) $\quad \mathrm{CH}_{4} \longleftrightarrow 2 \mathrm{C}+4 \mathrm{H}_{2}$

(11) $\quad 2 \mathrm{Fe}+2 \mathrm{H}_{2} \mathrm{O} \longleftrightarrow 2 \mathrm{FeO}+2 \mathrm{H}_{2}$

$$
\begin{aligned}
& 6 \mathrm{FeO}+2 \mathrm{H}_{2} \mathrm{O} \longleftrightarrow 2 \mathrm{Fe}_{3} \mathrm{O}_{4}+2 \mathrm{H}_{2} \\
& 6 \mathrm{FeO}+\mathrm{O}_{2} \longleftrightarrow 2 \mathrm{Fe}_{3} \mathrm{O}_{4} \\
& 4 \mathrm{Fe}_{3} \mathrm{O}_{4}+\mathrm{O}_{2} \longleftrightarrow 6 \mathrm{Fe}_{2} \mathrm{O}_{3}
\end{aligned}
$$

Table 2: Melting points of some common oxygen carriers

\section{Metal oxide and metal}

$\mathrm{Ni} / \mathrm{NiO}$
$\mathrm{Cu} / \mathrm{Cu}_{2} \mathrm{O} / \mathrm{CuO}$
$\mathrm{Fe} / \mathrm{FeO} / \mathrm{Fe}_{0.947} \mathrm{O} / \mathrm{Fe}_{3} \mathrm{O}_{4} / \mathrm{Fe}_{2} \mathrm{O}_{3}$
$\mathrm{Mn} / \mathrm{MnO} / \mathrm{Mn}_{3} \mathrm{O}_{4} / \mathrm{Mn}_{2} \mathrm{O}_{3}$
$\mathrm{Co} / \mathrm{CoO} / \mathrm{Co}_{3} \mathrm{O}_{4}$
$\mathrm{Sn} / \mathrm{SnO} / \mathrm{SnO}_{2}$
$\mathrm{Zn} / \mathrm{ZnO}$
$\mathrm{W} / \mathrm{WO}_{2} / \mathrm{WO}_{2.722} / \mathrm{WO}_{2.96} / \mathrm{WO}_{3}$

Melting point $\left({ }^{\circ} \mathrm{C}\right)$

$1455 / 1955$
$1085 / 1235 / 1446$
$1538 / 1377 / 1378 / 1597 / 1565$
$1246 / 1842 / 1562 / 1347$
$1495 / 1830$
$232 / 1042 / 1630$
$420 / 1975$
$3407 / 1724 /-/-/ 1472$

The phase equilibria of Fe-O-H and Fe-O-C are shown in Fig.3 ( $\mathrm{P}=1 \mathrm{~atm})$, indicating the suitable range of the operating temperature for the CLWS process. In order to achieve a high yield of $\mathrm{CO}_{2}$ (as opposed to $\mathrm{CO}$ ), the oxygen carrier should be present as $\mathrm{Fe}_{2} \mathrm{O}_{3}$, while Fe and $\mathrm{FeO}$ are thermodynamically favourable for $\mathrm{H}_{2}$ production. Therefore, $\mathrm{H}_{2}$ and $\mathrm{CO}_{2}$ are not here produced in the same reactor and a configuration of three reactors system is proposed as shown in Fig.3. In one reactor, the reducer (referring to the oxygen carrier) $\mathrm{CO}_{2}$ is produced and in another reactor (an oxidiser), $\mathrm{H}_{2}$ is produced via reaction of steam 
with $\mathrm{Fe}$ or $\mathrm{FeO}$. A third reactor (the air reactor) is used to regenerate the oxygen carrier. Similar configurations have been reported in earlier studies [3, 7, 25].

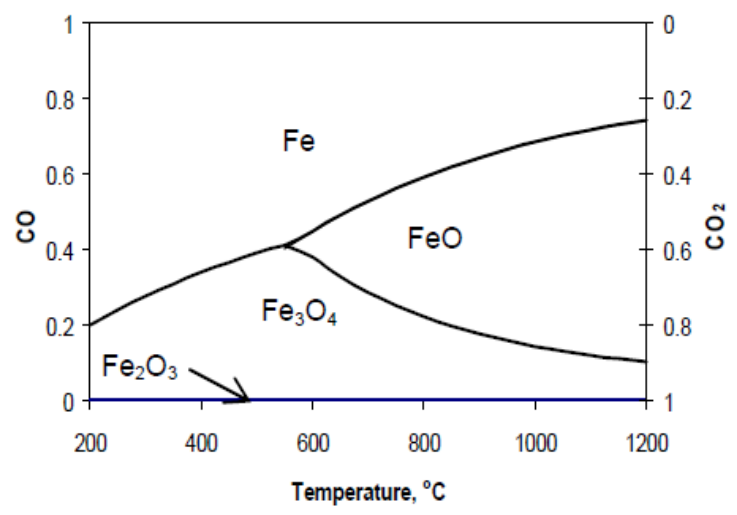

(a)

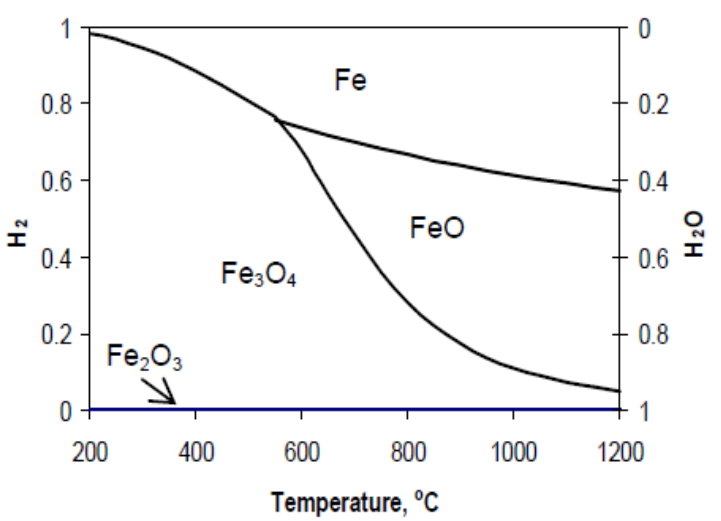

(b)

Fig. 3: The equilibrium phase diagram for: (a) Fe-C-O, (b) Fe-H-O at 1 bar total pressure [9].

\subsection{Description of the BCLWS Process:}

Natural gas is pre-heated and fed to the reducer, together with the regenerated oxygen carrier (47.3 mole\% $\mathrm{Fe}_{2} \mathrm{O}_{3}$ ) from the air reactor. In the reducer, natural gas is combusted to carbon dioxide and steam, while hematite is reduced to a mixture of iron and wustite ( $\mathrm{Fe}$ 0.947 $\mathrm{O}$ ), as shown from Fig. 6 in section 3.2 for the reducer operating parameters mentioned in Table 4. To maximize heat recovery, the reduced oxygen carrier is heated before being fed into the oxidiser. Using the pre-heated steam, the heated oxygen carrier is oxidized to magnetite, while $65.9 \%$ of the steam is converted to $\mathrm{H}_{2}$. This value of steam conversion was obtained based on the sensitivity performed on the process in section 3.2. The magnetite is then introduced to the air reactor with a pre-heated air stream in which magnetite is fully converted into hematite. Also, a stream containing unconverted hematite and magnetite at elevated temperature is fed to the air reactor to support the heat recovery from the solid among the process reactors. Moving bed reactors have been used here due to their better gas and solids contact, therefore higher gas and solids conversions in the reducer and oxidiser are observed [5, 7, 22, 36]. All the reactors operate at $\mathrm{P}=1.2 \mathrm{bar}$. The mixture of $\mathrm{CO}_{2}$ and steam is cooled to $30{ }^{\circ} \mathrm{C}$ in order to condense and separate the water. The dry $\mathrm{CO}_{2}$ is next compressed to 110 bar. The $\mathrm{H}_{2}$ and steam mixture is similarly cooled to $30^{\circ} \mathrm{C}$ to condense the steam out and separate the water. In order to further purify the $\mathrm{H}_{2}$, the hydrogen stream is compressed to $3 \mathrm{bar}$, hence removing more water via condensation. 
Through this process, a 99.4\% pure hydrogen stream is obtained. The corresponding process flow diagram and its components are shown in Fig. 4 and Table 3.

Table 3: List of the equipment illustrated on the BCLWS process flow diagram

Notation on the Figure

$$
\begin{gathered}
\mathrm{H}-\mathrm{i} \\
\mathrm{E}-\mathrm{i} \\
\mathrm{V}-\mathrm{i} \\
\mathrm{VL}-\mathrm{i} \\
\mathrm{C}-\mathrm{i}
\end{gathered}
$$

Reducer, Oxidiser, Combustor

\section{Equipment}

Heater

Coolers

Separation vessel

Valves

Compressors

Moving bed reactors

\begin{tabular}{|c|c|}
\hline Design specification & Specified value \\
\hline Temperature of natural gas fed to the reducer (bottom) & $600^{\circ} \mathrm{C}$ \\
\hline Temperature of the solids fed to the reducer (top) & $1050^{\circ} \mathrm{C}$ \\
\hline Temperature of the gas mixture discharged from reducer (top) & $1050^{\circ} \mathrm{C}$ \\
\hline Temperature of the solids discharged from reducer (bottom) & $651{ }^{\circ} \mathrm{C}$ \\
\hline Oxygen carrier to natural gas feed ratio & 6.7 \\
\hline Temperature of the solids fed to the oxidiser & $800{ }^{\circ} \mathrm{C}$ \\
\hline Temperature of the steam fed to the oxidiser & $500{ }^{\circ} \mathrm{C}$ \\
\hline Temperature of the wet hydrogen discharged from oxidiser & $680^{\circ} \mathrm{C}$ \\
\hline Temperature of the solids discharged from oxidiser & $820^{\circ} \mathrm{C}$ \\
\hline Oxygen carrier to steam ratio & 4.4 \\
\hline Air reactor temperature & $1015^{\circ} \mathrm{C}$ \\
\hline Separation vessel operating temperature & $30{ }^{\circ} \mathrm{C}$ \\
\hline Reactors operating pressure & $1.2 \mathrm{bar}$ \\
\hline Outlet pressure of $\mathrm{CO}_{2}$ compressor & 110 bar \\
\hline Outlet pressure of $\mathrm{H}_{2}$ compressor & 3 bar \\
\hline
\end{tabular}

\subsection{BCLWS Process Heat Integration}

Heat integration is a vital part of process optimization, resulting in the minimization of process heat going to waste [37].

Table 4: List of the operating parameters for the main units in the BCLWS process

One approach to heat integration is the use of heat exchangers to recover thermal energy from the process streams, leading to a minimisation in utility consumption [37, 38]. 


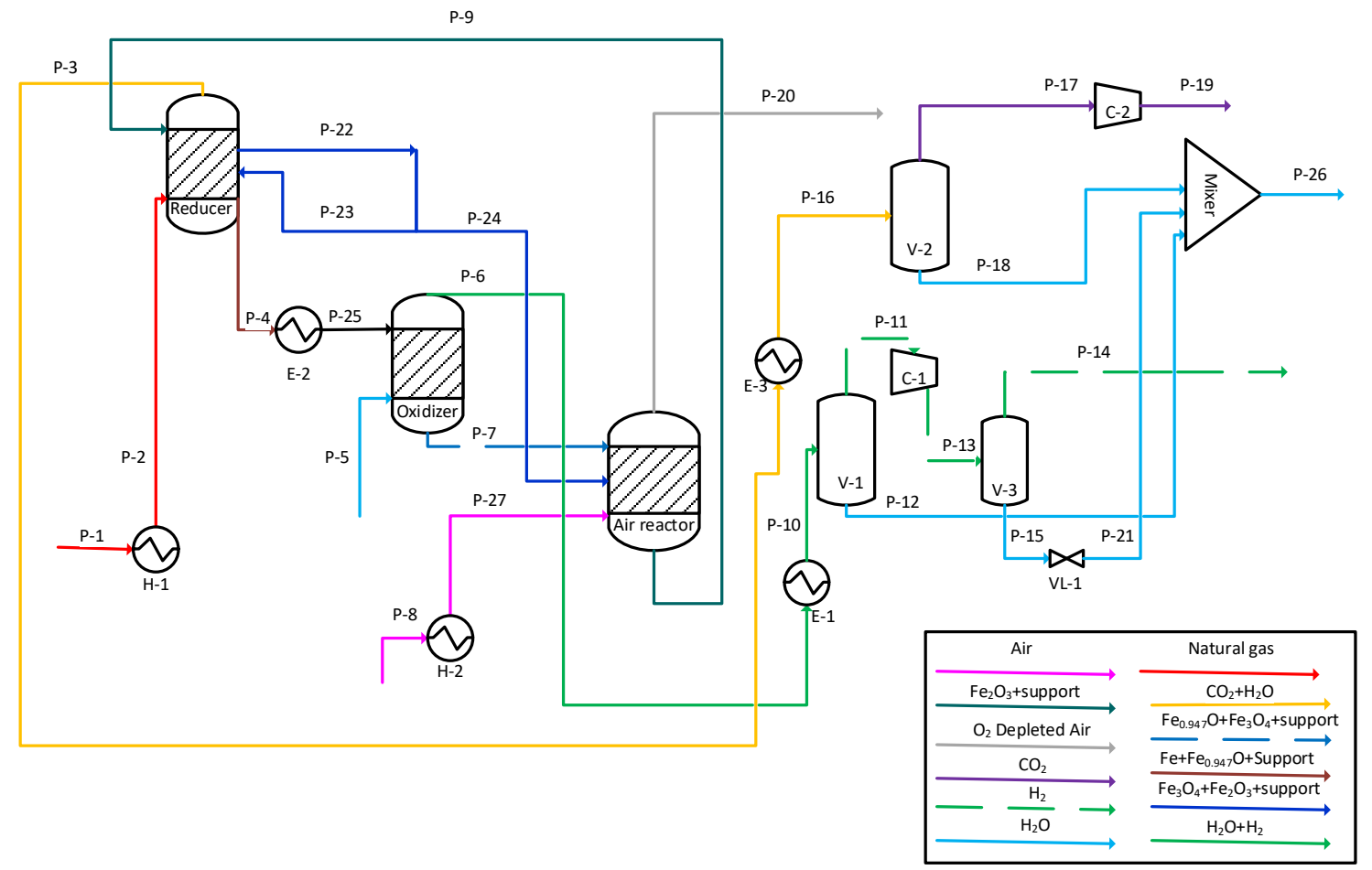

Fig. 4: The BCLWS process flow diagram

In this study, the pinch point method was employed to minimise the use of process utilities. A minimum temperature difference of $10^{\circ} \mathrm{C}$ between the hot and cold streams in the heat exchanger was assumed. The hot and cold streams involved in the heat integration analyses are shown in Fig. 5. Temperature intervals were selected based on the inlet and outlet temperatures of the corresponding streams (Fig. 5). The enthalpy associated with each stream in each of the intervals was then calculated and summed. The total enthalpy in interval 1 was then added to the one corresponding to the interval 2 . The resulting enthalpy was next added to the enthalpy in the subsequent interval. This procedure was repeated, forming the cascade heat duty for all the intervals shown in Table 5 . The cascade heat duty was then adjusted to determine the interval through which no heat was transferred. The minimum temperature associated with this interval is the pinch point temperature. The adjusted cascade heat duty is shown in Table 5. As can be seen, the $12^{\text {th }}$ interval corresponds to the pinch point i.e. $25^{\circ} \mathrm{C}$ on the cold temperature scale. This suggests that utility heating (71.5 MW) is needed for this particular interval. 


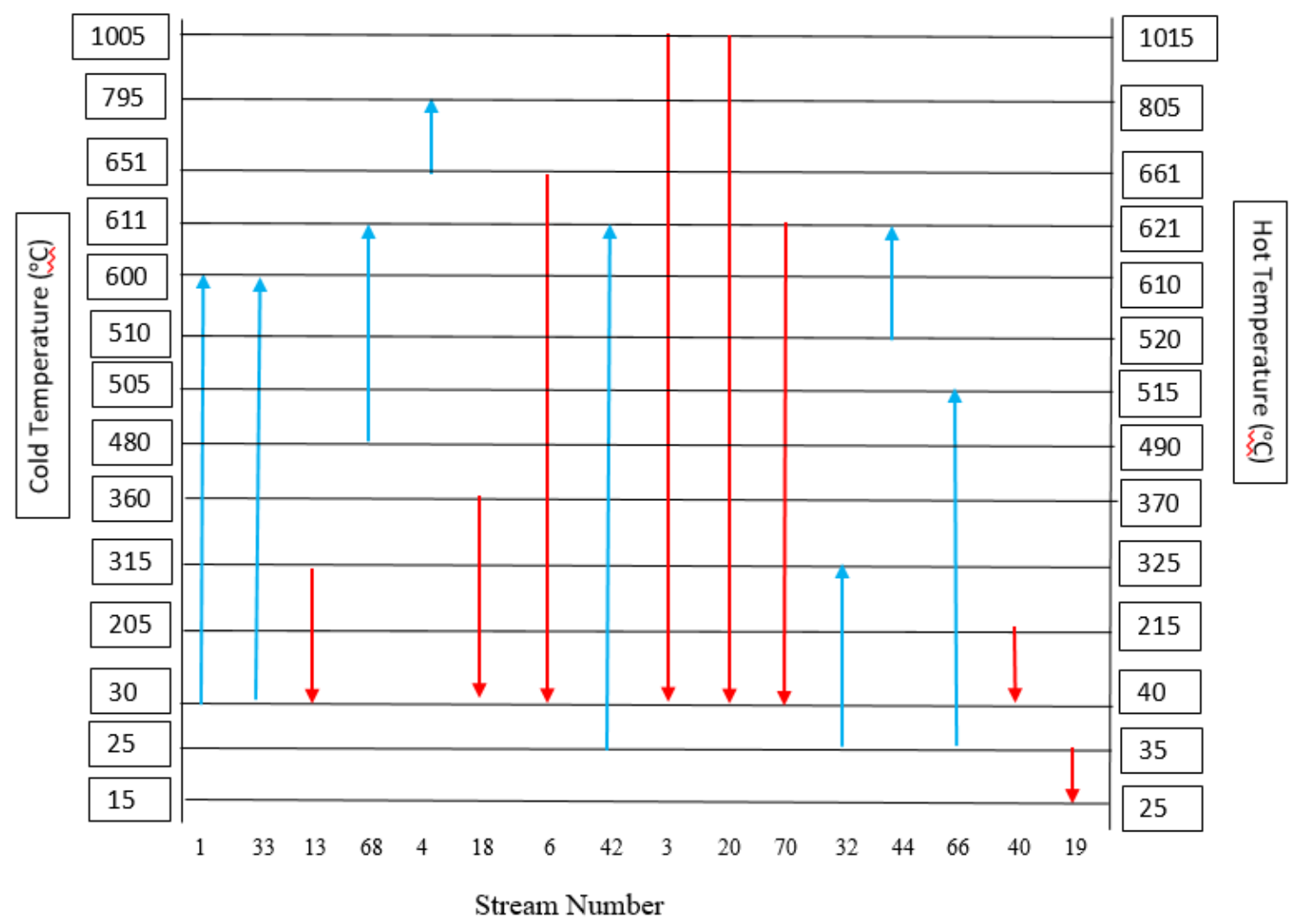

Fig. 5: The temperature intervals of the streams involved in the pinch point analysis for the BCLWS process A minimum utility cooling $(4.4 \mathrm{MW})$ is required below this particular interval. Accordingly, a heat exchanger network was designed (Fig. A1). The following considerations were made to improve the thermal and exergy efficiency of the process:

1- The $\mathrm{CO}_{2}$ compression to 110 bar was accomplished using 5 compressors with one inter-stage cooling system. This reduces the compression power consumption by $36 \%$ compared to the baseline process.

2- Considering water as the by-product of the process, and the large amount of heat released from the high temperature streams i.e. streams 73, 34, 39,70, 3 and 20, a water preheating unit (HE-(8-10)) followed by a heat recovery steam generation (HRSG-1) unit was added to vaporize the water and to generate power via the steam generation cycle.

3- The steam required in the oxidiser is generated by two units i.e. HRSG-2 and the fired heater (E-6) (Fig.A2). HRSG-2 comprises four parallel evaporators which use the heat energy released from the streams 18, 40, 74 and 51, respectively. In the 
fired heater, $5 \%$ of the syngas - generated in the bottom of the reducer (stream 26) - are fully combusted via their reaction with the pre-heated air.

The detailed heat integration analysis performed in this study has improved the process beyond the state of art in the literature. This can be seen specifically in the third consideration made during the heat exchanger network design. Splitting a high temperature gas stream (stream 26) from the reducer will improve the process performance due to the reduction of fuel consumption. This technique was not discussed in other previous studies when integrating a CLWS process.[7, 9, 10, 23, 25]. To show the effect of stream 26 on the process performance, natural gas replaced stream 26 in E-6 as shown in Fig. A4. This process is called CLWS(a). The thermodynamic evaluation of process CLWS(a) is included in Table 8.

\subsection{Sensitivity Analysis (Reducer and Oxidiser)}

Sensitivity analysis is a crucial step in optimising a chemical process [7, 23, 25]. The output (dependent) and the input (independent) parameters included in this study are summarized in Table 7 (a\&b). The Aspen Plus V.8.8 simulator was used to analyse the results. Based on the insights gained through the heat integration and sensitivity analysis, the BCLWS process has been optimized (ICLWS) (Fig. A2).

Table: 5: The cascade and the adjusted-cascade heat duty for each interval in the pinch point analysis

\section{Temperature interval $\left({ }^{\circ} \mathrm{C}\right)$}

$1+2(1015-805)+(805-661)$
$3(661-621)$
$4(621-610)$
$5(610-520)$
$6(520-515)$
$7(515-490)$
$8(490-370)$
$9(370-325)$
$10(325-215)$
$11(215-40)$
$12(40-35)$
$13(35-25)$

\section{Cascade Heat duty (MW)}

12.4

28.9

32.2

36.9

67.1

45.7

25.4

10.8

$-9.5$

$-66.9$

$-71.5$

$-67.1$
Adjusted Cascade Heat duty (MW)

83.9

100.4

103.7

108.4

138.7

117.2

96.9

82.3

62.0

4.6

0.0

4.4 
Table 6: List of the operating parameters of the main units in the ICLWS process.

Design specification

Reducer operating temperature

Temperature of the solids fed to the reducer

Temperature of the solids discharged from the reducer

Temperature of the natural gas fed to the reducer

Oxygen carrier to natural gas feed ratio

Temperature of the solids fed to the oxidiser

Temperature of the steam fed to the oxidiser

Operating temperature of the oxidiser

Temperature of the solids discharged from oxidiser

Oxygen carrier to steam ratio

Operating temperature of the air reactor

Separation vessels temperature

Operating pressure for all the reactors

Pressure of the $\mathrm{CO}_{2}$ product

Pressure of the $\mathrm{H}_{2}$ product

Isentropic efficiency of the compressors

Isentropic efficiency of the HP\&IP turbines

Isentropic efficiency of the LP turbine

Designed vapour fraction of the LP turbine

Pump efficiency

Inlet temperature of the Turbines

Pump outlet pressure

HP outlet pressure

IP outlet Pressure

LP outlet pressure
Specified value

$1015^{\circ} \mathrm{C}$

$1015^{\circ} \mathrm{C}$

$651^{\circ} \mathrm{C}$

$600{ }^{\circ} \mathrm{C}$

6.7

$795^{\circ} \mathrm{C}$

$505^{\circ} \mathrm{C}$

$661^{\circ} \mathrm{C}$

$820^{\circ} \mathrm{C}$

4.4

$1015^{\circ} \mathrm{C}$

$40{ }^{\circ} \mathrm{C}$

$1.2 \mathrm{bar}$

$110 \mathrm{bar}$

10.0 bar

0.90

0.90

0.87

0.9

0.85

$611^{\circ} \mathrm{C}$

260 bar

150 bar

$70 \mathrm{bar}$

0.026 bar

\section{Results and Discussion}

\subsection{Thermodynamic Analyses}

The process was thermodynamically analysed by assessing the thermal efficiency of the process and the hydrogen yield using Eqs.15-20 [4].

Table 7 (a): List of the output parameters studied in this study

Output parameter

Gas outlet conversion in the reducer

Discharged solid conversion in the reducer

Gas outlet conversion in the oxidiser

Discharged solid conversion in the oxidiser
Symbol $X_{g r}$

$X_{s r}$

$X_{g o}$

$X_{\text {so }}$ 
Table 7 (b): List of the input parameters studied in this analysis

\begin{tabular}{|c|c|c|c|c|}
\hline \multicolumn{2}{|c|}{ Input parameter } & Symbol & Span & Step size \\
\hline \multicolumn{2}{|c|}{ Oxygen carrier-to-methane feed ratio } & $R_{1}=F_{\text {od }} F_{C H 4 i}$ & $1-7.6$ & 0.2 \\
\hline \multicolumn{2}{|c|}{ Oxygen carrier-to-steam feed ratio } & $R_{2}=F_{o d} F_{s i}$ & $2-6$ & 0.2 \\
\hline \multicolumn{2}{|c|}{ Reducer’s discharged gas temperature } & $T_{g r}$ & $700-1020$ & 20 \\
\hline \multicolumn{2}{|c|}{ Reducer's discharged solid temperature } & $T_{s r}$ & $600-900$ & 20 \\
\hline \multicolumn{2}{|c|}{ Oxidiser’s discharged gas temperature } & $T_{g o}$ & $620-900$ & 20 \\
\hline \multicolumn{2}{|c|}{ Oxidiser's discharged solid temperature } & $T_{\text {so }}$ & $620-900$ & 20 \\
\hline$\eta_{t h}=\frac{\dot{Q}_{o}}{\dot{Q}_{i}}$ & $(15)$ & & & \\
\hline$\eta_{H_{2}}=\frac{\dot{Q}_{o}}{\dot{Q}_{f}}$ & (16) & & & \\
\hline$\eta_{e f f}=\frac{Q_{j}-P_{c / g}}{Q_{i}}$ & $(17)$ & & & \\
\hline$\dot{Q}_{o}=\dot{m}_{H_{2}} H H V_{H_{2}}$ & (18) & & & \\
\hline$\dot{Q}_{i}=\dot{m}_{N G} H H V_{N G}+\dot{Q}_{M H}$ & (19) & & & \\
\hline$\dot{Q}_{f}=\dot{m}_{N G} H H V_{N G}$ & (20) & & & \\
\hline
\end{tabular}

Where $\dot{m}_{H_{2}}$ and $\dot{m}_{N G}(\mathrm{~kg} / \mathrm{s})$ are the mass flow rates of $\mathrm{H}_{2}$ produced and natural gas consumed by the process, respectively. $F_{H_{2}}$ and $F_{N G}$ are the mole flow rates of $\mathrm{H}_{2}$ produced and natural gas consumed by the process, respectively. HHV is the higher heating value of the fuel $(54.1 \mathrm{MJ} / \mathrm{kg})[39,40] . P_{c / g}$ is the power generated (-ve) through turbines or consumed (+ve) through pumps and compressors in the process. $\dot{Q}_{M H}$ is the net heating utility in MW, supplied to the process. $\eta_{\text {eff }}$ is the effective efficiency. The corresponding values of all these parameters are summarized in Table 8. These parameters were identical for both support materials used in this work. It is seen that the optimised process has improved by 31.1\% for its thermal energy compared with the baseline process (BCLWS). For hydrogen efficiency, the ICLWS process shows improvements in efficiency by $23.7 \%$ and 2.8\% compared with the baseline process and the no split process (CLWS(a)). Also, it is improved by $11.7 \%, 6.5 \%$ and $13.4 \%$ in comparison to the conventional SMR [4], the Ohio State University process [7] and TRCLR proposed by Khan and Shamim from the Centre for Energy in Abu Dhabi [25], respectively. Also, The ICLWS process corresponds 
to the largest effective efficiency among these processes; it is $11.9 \%, 6.5 \%$ and $10.8 \%$ higher compared to the SMR, OSU and TRCLR processes, respectively. It is $41.3 \%$ higher than the baseline process. This is attributed to the amount of power generated by the steam generation cycle within this process which was missing for both the SMR and the OSU processes as well as the basic process and significantly less is generated in the TRCLR. In addition, the effective efficiency for the ICLWS is $4.1 \%$ higher than the no split process CLWS(a). Using $5 \%$ of the syngas in this way improved the developed process performance by $2.8 \%$ and $4.1 \%$ in terms of the hydrogen and effective efficiency. However, it lowers the $\mathrm{CO}_{2}$ capture by $1.5 \%$.

\subsection{Sensitivity Analyses (Reducer)}

The effect of oxygen carrier to methane feed ratio on the conversion of the discharged gas and solid is shown in Fig. 6. The reducer discharged gas temperature and pressure are set at $1015{ }^{\circ} \mathrm{C}$ and 1.2 bar, respectively. It is observed that the gas conversion increases with an increase in the ratio of the oxygen carrier to the methane fed. Similar trends have been reported in the literature $[7,19]$ under similar operating conditions with different oxygen carrier supports. This results from the extent of combustion taking place in the reducer [19].

Table 8: Comparison of the thermodynamic evaluation of the optimized, basic, SMR and the OSU processes

\begin{tabular}{|c|c|c|c|c|c|c|}
\hline Parameter & $\operatorname{SMR}^{[4]}$ & OSU ${ }^{[7]}$ & $T R C L R^{[25]}$ & BCLWS & CLWS(a) & ICLWS \\
\hline $\mathrm{CO}_{2}$ capture $\%$ & 90.0 & 90.0 & 100 & 69.2 & 88.8 & 87.3 \\
\hline$\frac{F_{H_{2}}}{F_{N G}}$ & 2.30 & 2.29 & 2.54 & 1.96 & 2.63 & 2.72 \\
\hline$\dot{\boldsymbol{Q}}_{\boldsymbol{i}}(M W)$ & N/A & N/A & - & 2116.6 & 1354.4 & 1285.2 \\
\hline$\dot{\boldsymbol{Q}}_{\boldsymbol{o}}(M W)$ & 1012.6 & 1017.9 & 291.5 & 1021.0 & 1021.0 & 1019.2 \\
\hline$\dot{\boldsymbol{Q}}_{\boldsymbol{f}}(M W)$ & 1402.9 & 1309.4 & 413.3 & 1696.1 & 1258.2 & 1215.7 \\
\hline $\boldsymbol{P}_{c / g}(M W)$ & 34.2 & 33.4 & 1.6 & 78.6 & -28.3 & -29.5 \\
\hline $\boldsymbol{\eta}_{t h}$ & - & - & - & 48.2 & 75.2 & 79.3 \\
\hline$\eta_{\mathrm{H}_{2}}$ & 72.2 & 77.6 & 70.5 & 60.2 & 81.1 & 83.9 \\
\hline$\eta_{e f f}$ & 69.7 & 75.1 & 70.8 & 40.3 & 77.5 & 81.6 \\
\hline
\end{tabular}




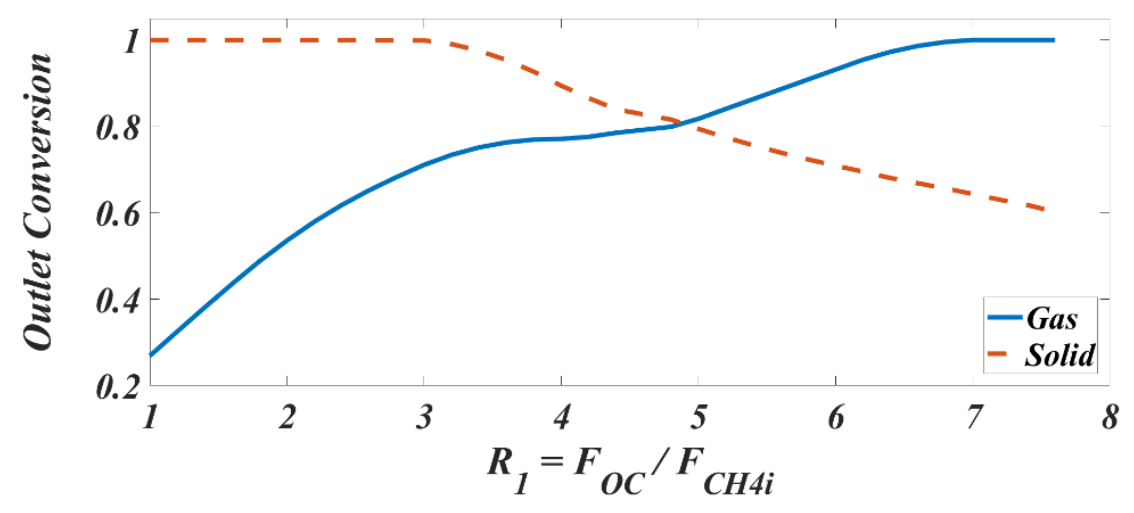

Fig. 6: The effect of $R_{1}$ on the conversion of the discharged gas and solid in the reducer

As the $R_{1}$ increases, reactions $4-5$ can move closer to completion, moving the equilibrium state of reactions 7-9 toward complete combustion. The addition of a discharged solid stream $\left(12 \% \mathrm{Fe}_{2} \mathrm{O}_{3}\right.$ and $\left.28 \% \mathrm{Fe}_{3} \mathrm{O}_{4}\right)$ leaving the reducer results in improving both the conversion of solid and the heat recovery from the reactors. Reducing the amount of $\mathrm{Fe}_{2} \mathrm{O}_{3}$ and $\mathrm{Fe}_{3} \mathrm{O}_{4}$ in the reducer effects the amount of $\mathrm{Fe}_{0.947} \mathrm{O}$ produced via reaction 8 . This increases the amount of $\mathrm{Fe}$ in the discharged solid. The conversion of solid exhibits contrasting behaviour to that of the gas conversion. For the $R_{1}$ values below 3.4, ferrous iron represents the only form of oxygen carrier in the reduced solid. Therefore, the conversion of solid is $100 \%$. For $R_{1}>3.4$, wustite is co-generated in addition to Fe. This consequently results in a linear reduction in solid conversion [19].

The effect of the reducer's outlet temperature on the gas conversion is shown in Fig. 7.

Fig. 7 shows that the outlet gas conversion is enhanced with an increase in the reducer's outlet temperature until complete conversion is achieved at $\mathrm{Tgr}_{\mathrm{gr}}=940{ }^{\circ} \mathrm{C}$. This is a reasonable trend due to the endothermic nature of the reactions (4-10), taking place in the reducer. Similar results have been reported in the literature [19]. Increasing $T_{\mathrm{gr}}$ tends to move the equilibrium state in reactions $4-5$ to the right and therefore shifts the equilibrium states in reactions 7-8. This consequently results in complete combustion. Fig. 8 demonstrates the effect of solids' outlet temperature on the solids conversion. 


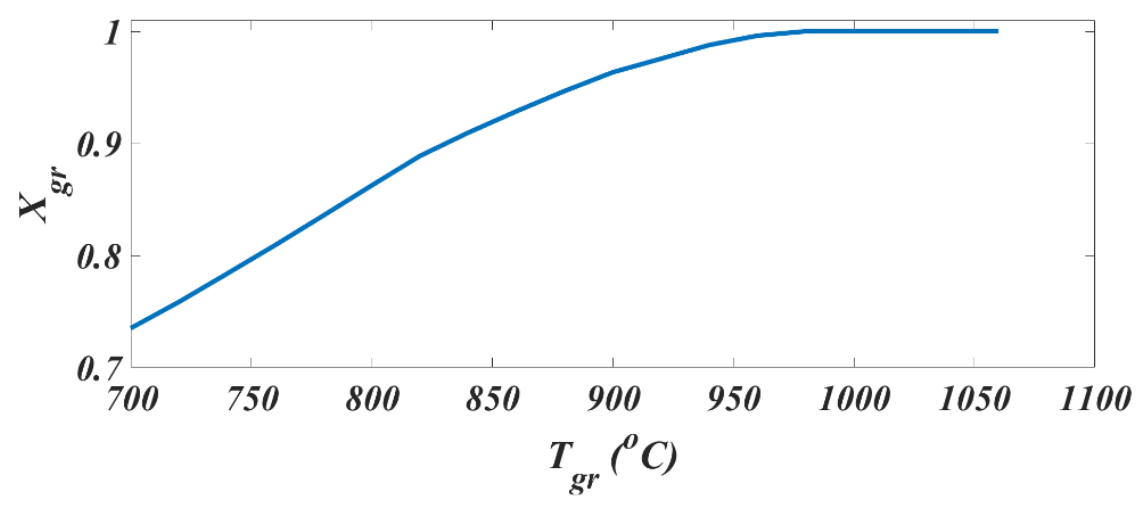

Fig. 7: The effect of the reducer's outlet gas temperature on the conversion $\left(R_{1}=6.8\right.$ and $\left.T_{s r}=651^{\circ} \mathrm{C}\right)$

It is seen that with an increase in the outlet temperature, the solid conversion increases to a maximum value of 0.66 at $\mathrm{T}_{\mathrm{sr}}=651^{\circ} \mathrm{C}$. This is linked to the amount of carbon deposited on the discharged solid (reaction 10 in Table 1). As the temperature of the discharged solid rises, carbon deposition is reduced, resulting in an enhancement in the conversion of the solid. A further increase in the discharged solid temperature to above $651^{\circ} \mathrm{C}$ does not affect the conversion of the solid. No carbon deposition is observed at these elevated temperatures.

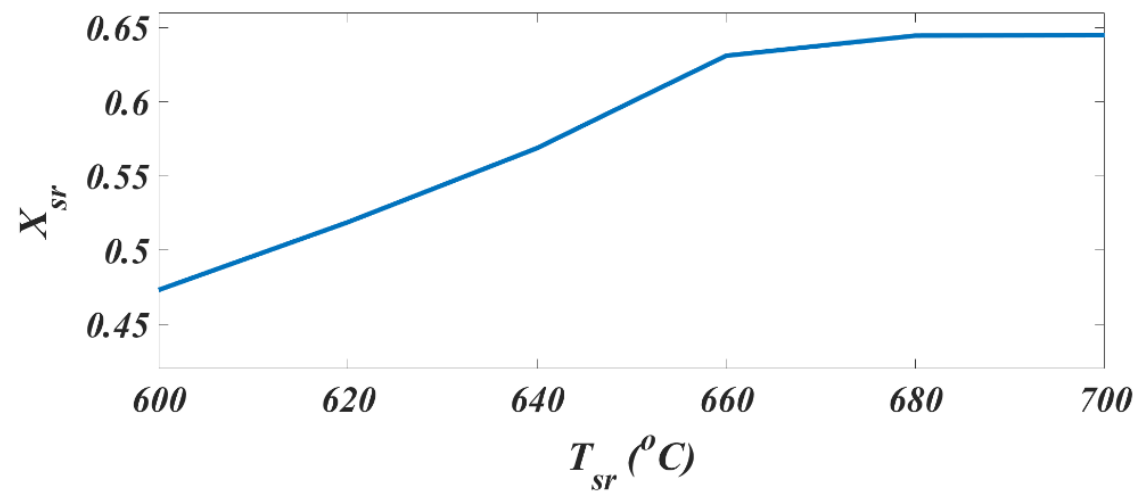

Fig.8: The effect of the discharged solid temperature on the conversion of the solid

\subsection{Sensitivity Analyses (Oxidiser)}

The variations of the discharged gas and solid conversion ratios as a function of steam-tomethane ratios are shown in Fig. 9. 


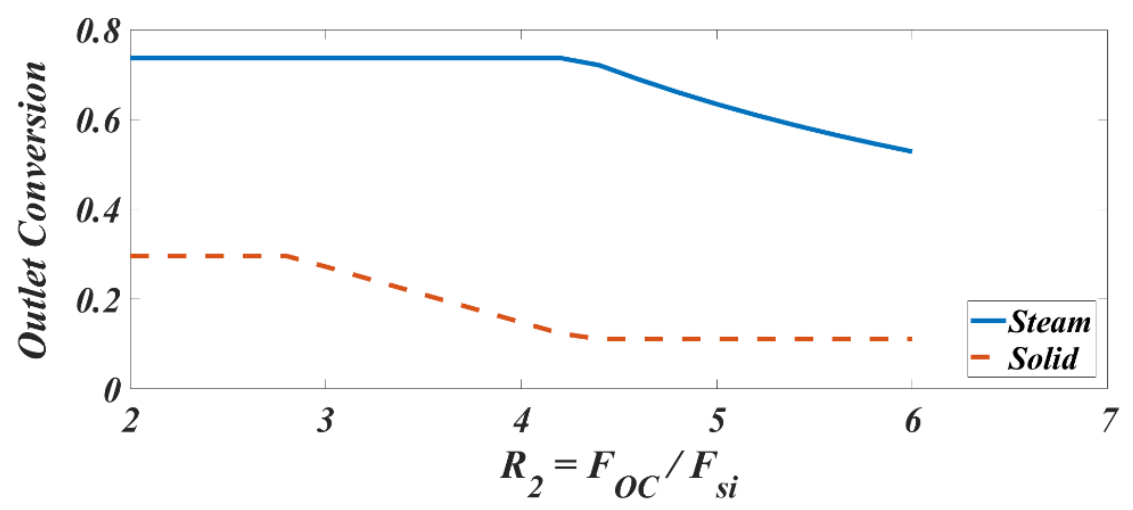

Fig. 9: The effect of the steam-to-methane inlet flow ratio on the oxidiser's discharged gas and solid conversions for $\left(T_{g o}=660^{\circ} \mathrm{C}, T_{s o}=820^{\circ} \mathrm{C}\right.$ and $\left.X_{s r}=0.66\right)$

With $R_{2} \leq 4.4$, the discharged gas conversion remains constant at $71 \%$ (Fig. 9). However, it steadily declines as $R_{2}$ increases. For $2.8 \leq R_{2} \leq 4.4$, the conversion ratio almost linearly decreases with an increase in $R_{2}$. For $R_{2} \geq 4.4$, there is little variation in the conversion ratio. Similar trends with alumina as support have been reported in the literature [7]. The observed curvature in Fig. 9 can be explained via the thermodynamic analysis of the oxidiser- and oxygen carrier's reactions (11-12 in Table 1$)$. For $R_{2} \leq 4.4$, the reactions 1112 tend to move to the right i.e. more hydrogen is produced. However, the amount of hydrogen produced is equivalent to the amount of steam fed. Consequently, the steam conversion remains constant. For $R_{2} \geq 4.4$, the value of the solid conversion is $11 \%$. This conversion value corresponds to pure magnetite. Thermodynamically, wustite and ferrous iron are the required forms of the iron-based oxygen carriers for hydrogen production. The solid conversions exhibit different behaviour from that of the steam conversion. For $2 \leq R_{2}$ $\leq 2.8$, the amount of steam fed to the oxidiser is only sufficient to activate reaction 11 based on the stoichiometry of reactions 11-12. This suggests that the discharged solid is made up of wustite only. Reaction 11 indicates that in order to generate a mole of wustite and hydrogen, one mole of steam is require to react with one mole of ferrous iron. In reaction 12 , each mole of steam requires three moles of wustite to produce one mole of hydrogen and magnetite and therefore, more wustite is needed to activate reaction 11. For $2.8<R_{2}$ $\leq 4.4$, reaction 12 is activated by continuous generation of wustite via reaction 11 . Therefore, the equilibrium state of reaction 12 moves to the right until all the wustite has been converted to magnetite at an $R_{2}$ value of 4.4. 
The effects of the oxidiser's discharged gas and solid temperature on the oxidiser's discharge gas and solid conversions are shown in Fig. 10 (a) and (b).

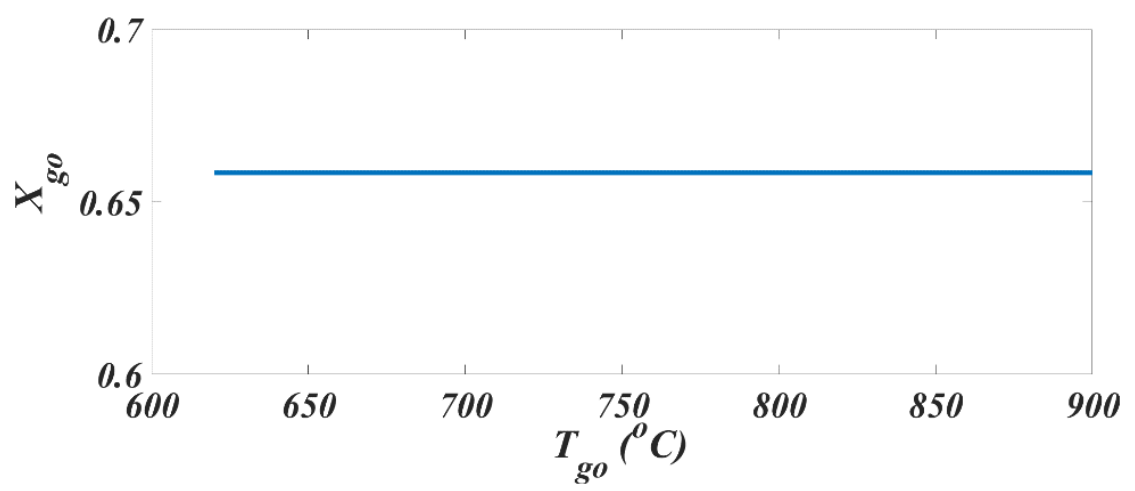

Fig. 10 (a): The effect of the oxidiser's outlet gas temperature on the oxidiser's outlet gas conversion $\left(R_{2}=\right.$ 4.4 and $\left.X_{s r}=0.66\right)$

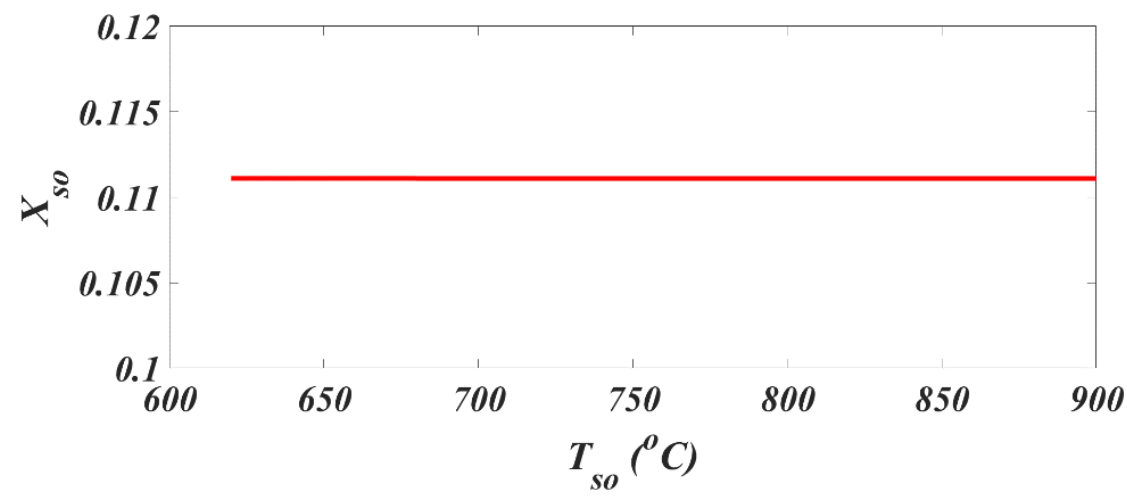

Fig. 10 (b): The effect of the oxidiser's outlet gas temperature on the oxidiser's outlet solid conversion $\left(R_{2}=\right.$ 4.4 and $\left.X_{s r}=0.66\right)$

It is seen (Fig.10 ( $a$ and b)) that both the discharged solid and gas temperatures have a negligible impact on the conversion in the oxidiser. Under these operating conditions, the discharged solid conversion is $11 \%$ i.e. hydrogen is not produced in the oxidiser.

\section{Economic Assessment of the Process}

The techno-economics of the process were investigated by determining the corresponding total investment cost and the total operating cost to estimate the hydrogen production cost 
in $\$ / \mathrm{kg}$. The results were compared with the benchmark SMR process [4]. The production cost for the SMR process was adjusted based on the fuel prices in 2017 to be $1.64 \$ / \mathrm{kg}$ [39]. The total investment cost was calculated following the "Lang" method. In this method, the total investment is obtained by multiplying the total equipment cost by the factors included in Table 9, and were costed according to the method of Couper et al [41]. Table 12 shows the associated equipment costings [42, 43]. Reactors' sizing was done via the mass and energy balance around each component as well as the reactor [44, 45]. The chemical and physical properties of gas and solid as well as the kinetics associated with reactions 4-14 were retrieved from the earlier studies [34, 46]. Although the kinetics were derived for $\mathrm{Fe}_{2} \mathrm{O}_{3}$ over the $\mathrm{ZrO}_{2}$ support, it was assumed that the kinetics are correct for $\mathrm{Fe}_{2} \mathrm{O}_{3}$ over the $\mathrm{MgAl}_{2} \mathrm{O}_{4}$ support $[34,46]$. The Oxygen carrier makeup cost was based on the Abad and Adanez equation [36]. Vapour- liquid separators were sized by adopting the Gerunda approach [47]. The dimensions of these parameters determine their purchased cost [42]. Other Parameters such as heat transfer area, total heat load, net work were obtained from Aspen simulation to determine the purchased cost for heat exchangers, HRSG units and pressure change equipment, respectively via the correlations and figures found in the literature [42, 43]. The total investment and operating costs are summarised in Tables 13 and 1 , respectively.

Table 9: Assumptions used in the determination of the total capital investment for the optimised process [41]

\% equipment

Cost type

delivered cost
Direct cost (equipment installation, Instrumentation, piping, electrical system, buildings, labours and service facilities) Indirect cost (Engineering supervision, construction, legal expenses, contractor's fee, contingency)
Working capital (15\% of the total capital investment) Total capital investment

302

126 75

503

The calculated value for the production cost of hydrogen $(\$ / \mathrm{kg})$ for SMR process [4] is $14 \%\left(\mathrm{MgAl}_{2} \mathrm{O}_{4}=\mathrm{a}\right)$ and $1.2 \%\left(\mathrm{ZrO}_{2}=\mathrm{b}\right)$ higher lower compared to the ICLWS process. Also, the hydrogen production cost for the ICLWS process is $19.1 \%$ (a) and $3.6 \%$ (b) lower 
compared to the TRCLR process proposed by Khan from the Centre for Energy in Abu Dhabi [25].

Table 10: Operating parameters assumed in this study

\begin{tabular}{c|cc}
\multicolumn{1}{c}{ Parameter } & Value & Reference \\
\hline Fuel (natural gas) & $0.17 \$ / \mathrm{kg}$ & {$[39]$} \\
Iron oxide & $0.072 \$ / \mathrm{kg}$ & {$[48]$} \\
$\mathrm{MgAl}_{2} \mathrm{O}_{4}$ & $0.63 \$ / \mathrm{kg}$ & {$[48]$} \\
$\mathrm{ZrO}_{2}$ & $4.68 \$ / \mathrm{kg}$ & {$[48]$} \\
Iron oxide makeup percentage required & $1 \% / 15 \mathrm{~h}$ & {$[9]$} \\
Power consumption of Iron oxide manufacturing & $22 \mathrm{kWh} / \mathrm{t}$ & {$[48]$} \\
Plant operating time in a year & 328 days & {$[4]$} \\
Electricity (selling price) & $0.07 \$ / \mathrm{kWh}$ & {$[49]$} \\
Cooling water & $1.03 \$ / \mathrm{m}^{3}$ & {$[50]$}
\end{tabular}

Table 11: Operating cost parameter calculations

Operating cost parameters

Electricity
Cooling water
Fuel
Iron oxide and support make up $\left(\mathrm{MgAl}_{2} \mathrm{O}_{4}\right)$
Iron oxide and support make up $\left(\mathrm{ZrO}_{2}\right)$
Total $\left(\mathrm{MgAl}_{2} \mathrm{O}_{4}\right)$
Total $\left(\mathrm{ZrO}_{2}\right)$

Total consumption Cost (M\$/year)

\begin{tabular}{|c|c|}
\hline$-29.5 \mathrm{MW}$ & -16.4 \\
$130 \mathrm{Mm}^{3} / \mathrm{yr}$ & 136.3 \\
$0.64 \mathrm{Mt} / \mathrm{yr}$ & 105.9 \\
$0.022 \mathrm{Mt} / \mathrm{yr}$ & 23.1 \\
$0.02 \mathrm{Mt} / \mathrm{yr}$ & 65.3 \\
& 246.5 \\
& 289.0 \\
\hline
\end{tabular}

The capacity of this plant is 3.5 times that of the TRCLR. Hence, the rate of the fuel consumption as well as the water generated is higher in this process. Consequently, the amount of cooling water used in the condenser will be higher. In addition, the equipment is larger and the quantity of labour required is higher. All these factors lead to a larger operating and capital cost compared with the TRCLR process. However, the high production rate of hydrogen for the ICLWS process leads to a lower hydrogen production cost per unit mass. Despite the fact that the SMR operating cost is $18.7 \%$ (a) and $39.1 \%$ (b) lower than the ICLWS process, the inherent $\mathrm{CO}_{2}$ capture nature of the ICLWS process 
makes its capital cost $45.5 \%$ lower compared to SMR with $\mathrm{CO}_{2}$ capture. Therefore the hydrogen production cost $(\$ / \mathrm{kg})$ for the ICLWS $\left(\mathrm{MgAl}_{2} \mathrm{O}_{4}\right)$ process is overall lower.

Table 12: The list of the equipment unit prices as estimated in this work

\section{Equipment $\quad$ Purchased price (M\$)}

\begin{tabular}{c|c}
\hline Reducer & 0.32 \\
Oxidiser & 1.22 \\
Combustor & 0.34 \\
Heat exchangers & 1.04 \\
HRSG-1 & 8.00 \\
HRSG-2 & 2.12 \\
Fired heater (E-6) & 1.77 \\
Indirect solid-gas heater (E-5) & 0.72 \\
LP + IP + HP Turbine & 11.46 \\
CO 2 compressors & 8.01 \\
H2 compressors & 7.63 \\
Coolers & 0.24 \\
Separation vessels & 12.34 \\
Water preheater & 3.84 \\
Surface condenser & 2.52 \\
Pump & 0.014 \\
Total & 63.22
\end{tabular}

Table 13: Total investment cost, annualized operating cost and first-year cost calculation

\begin{tabular}{|l|l|l|l|l|}
\hline Parameter & ICLWS (a) & ICLWS (b) & SMR & TRCLR \\
\hline Total investment Cost = 5.03 x Purchased cost (M\$) & 369.6 & 369.6 & 678.1 & 174.5 \\
\hline Total operating cost (M\$/yr) & 246.5 & 289.0 & 207.7 & 87.5 \\
\hline Hydrogen produced (Mt/yr) & 0.24 & 0.24 & 0.24 & 0.055 \\
\hline Interest rate (\%) & 10 & 10 & 10 & N/A \\
\hline Plant lifetime (yr) & 25 & 25 & 25 & 30 \\
\hline Total annual cost (M\$) & 287.2 & 329.7 & 332.7 & 92.4 \\
\hline $\mathrm{H}_{2}$ production cost (\$/kg $\left.\mathrm{H}_{2}\right)$ & 1.41 & 1.62 & 1.64 & 1.68 \\
\hline
\end{tabular}


- $\quad$ ICLWS (a) = ICLWS with $\mathrm{MgAl}_{2} \mathrm{O}_{4}$ support material

- $\quad$ ICLWS (b) = ICLWS process with $\mathrm{ZrO}_{2}$ support material

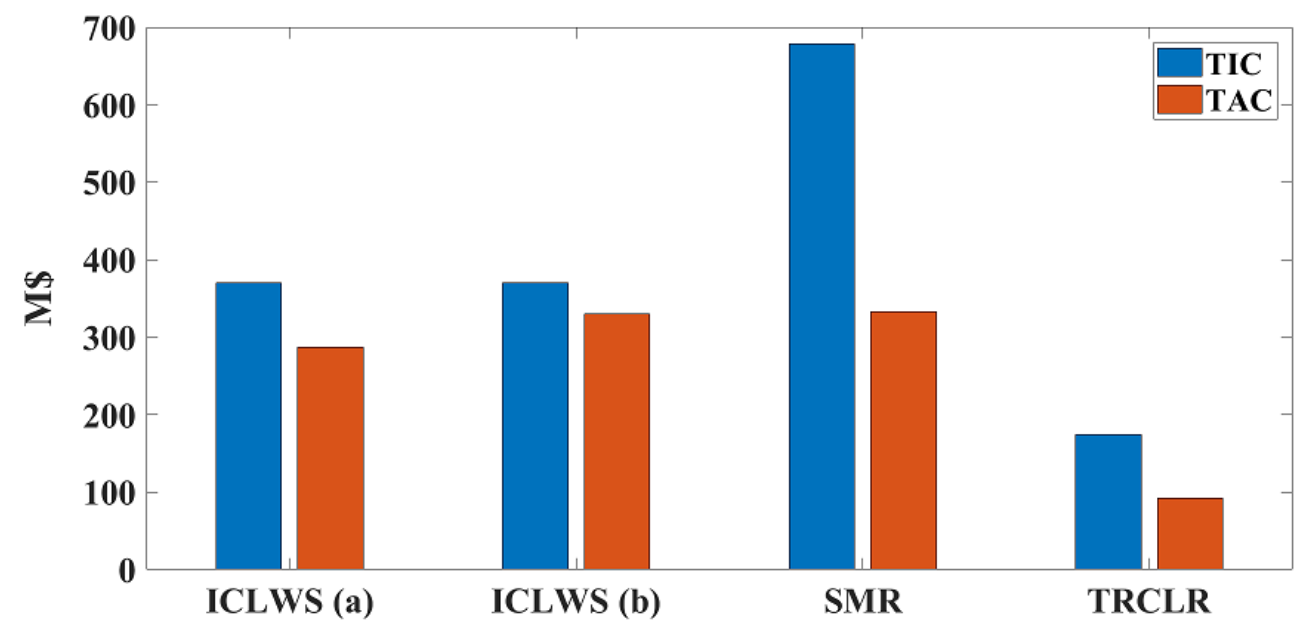

Fig.11: comparison between the SMR, ICLWS and TRCLR for total investment cost (TIC) and annualized operating cost (TAC).

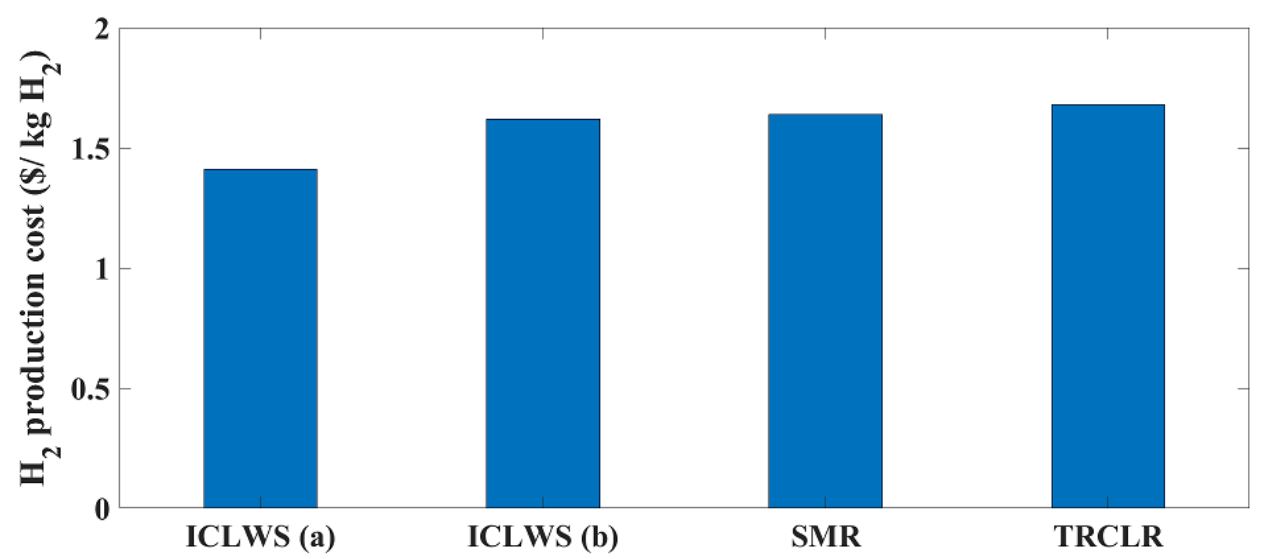

Fig.12: comparison between the SMR, ICLWS and TRCLR for $\mathrm{H}_{2}$ production cost

\section{Conclusions}

A hydrogen production process with integrated $\mathrm{CO}_{2}$ capture via chemical looping technology using three moving bed reactors has been developed and simulated using Aspen Plus V8.8. The process was then optimized by performing heat integration analysis and sensitivity analysis for the main process parameters. The heat integration analysis results in a heat exchanger network coupled with three HRSG units, and a fired heater employed to generate the steam required by the oxidiser and steam generation cycles to produce power. In the sensitivity analysis for the reducer, it is observed that the conversion of the 
discharged gas increases as the oxygen carrier to methane ratio and the temperature of the discharged gas increase until a complete conversion is achieved.

The conversion of the discharged solids increases to a certain value as the temperature increases. For this value of the discharged temperature the carbon deposition inside the reducer is zero. On the other hand, the conversion of the discharged solids decreases as the oxygen carrier to methane ratio increases.

For the oxidiser, the steam outlet conversion remained constant for a certain range of the ratio of oxygen carrier to methane fed. After, it starts to decrease when all the wustite is fully converted to magnetite. The conversion of the discharged solids decreases as the ratio increases until all the wustite is fully oxidized.

The process was evaluated by determining its thermal and hydrogen efficiency. The process thermal energy was $79.3 \%$ whereas its hydrogen efficiency is $83.9 \%$. The effective and hydrogen the efficiencies of the ICLWS process are $11.7 \%, 6.3 \%$ and 13.4 higher compared with the SMR, OSU and TRCLR processes, respectively.

The optimised process was evaluated economically by determining the total investment cost, operating cost and the hydrogen production cost per unit mass, for a number of different support materials. The ICLWS $\left(\mathrm{MgAl}_{2} \mathrm{O}_{4}\right)$ and $\left(\mathrm{ZrO}_{2}\right)$ has $14 \%$ and $1.2 \%$ lower hydrogen production costs than SMR, respectively. Also, its hydrogen production cost is $16.1 \%\left(\mathrm{MgAl}_{2} \mathrm{O}_{4}\right)$ and 3.6\% $\left(\mathrm{ZrO}_{2}\right)$ lower compared to the TRCLR process. Based on the thermodynamic and the economic evaluation, producing hydrogen via chemical looping can be considered a promising future technology; further research should be conducted considering the operation and handling of solids in the reactors and throughout the process. 


\section{References}

1. Bohn, C., The production of pure hydrogen with simultaneous capture of carbon dioxide. 2010.

2. Fan, L.-S., et al., Chemical looping processes for $\mathrm{CO} 2$ capture and carbonaceous fuel conversion prospect and opportunity. Energy Environ. Sci., 2012. 5(6): p. 7254-7280.

3. Fennell, P.e. and B.e. Anthony, Calcium and chemical looping technology for power generation and carbon dioxide (CO2) capture. 2015.

4. Rath, L.K., Assessment of Hydrogen Production with $\mathrm{CO}_{2}$ Capture Volume 1: Baseline State-of-the-Art Plants. 2010, National Energy Technology Laboratory: USA.

5. Zeng, L., Multiscale Study of Chemical Looping Technology and Its Applications for Low Carbon Energy Conversions, L.-S. Fan, A. Asthagiri, and W. Ho, Editors. 2012.

6. Use, C.O.A. and A. Strategies For Future Hydrogen Production, The Hydrogen Economy: Opportunities, Costs, Barriers, and R\&D Needs, E. United States. Department Of Energy. Office Of Energy and E. Renewable, Editors. 2004.

7. Kathe, M.V., et al., Hydrogen production from natural gas using an iron-based chemical looping technology: Thermodynamic simulations and process system analysis. Applied Energy, 2016. 165: p. 183-201.

8. Dittmar, B., et al., Methane steam reforming operation and thermal stability of new porous metal supported tubular palladium composite membranes. International Journal of Hydrogen Energy, 2013. 38(21): p. 8759-8771.

9. Li, F., Chemical looping gasification processes, L.-S. Fan, Editor. 2009.

10. Fan, L.-S., et al., Chemical looping processes for $\mathrm{CO} 2$ capture and carbonaceous fuel conversion - prospect and opportunity. Energy \& Environmental Science, 2012. 5(6): p. 7254-7280.

11. Moghtaderi, B., Review of the Recent Chemical Looping Process Developments for Novel Energy and Fuel Applications. Energy \& Fuels, 2012. 26(1): p. 15-40.

12. Luo, M., et al., Review of hydrogen production using chemical-looping technology. Renewable and Sustainable Energy Reviews, 2018. 81(P2): p. 3186-3214.

13. Dou, B., et al., Hydrogen production and reduction of Ni-based oxygen carriers during chemical looping steam reforming of ethanol in a fixed-bed reactor. International Journal of Hydrogen Energy, 2017. 42(42): p. 26217-26230.

14. Dou, B., et al., Hydrogen production from the thermochemical conversion of biomass: issues and challenges. Sustainable Energy Fuels, 2019. 3(2): p. 314-342.

15. Rydén, M., A. Lyngfelt, and T. Mattisson, Synthesis gas generation by chemical-looping reforming in a continuously operating laboratory reactor. Fuel, 2006. 85(12): p. 16311641.

16. Zafar, Q., T. Mattisson, and B. Gevert, Integrated Hydrogen and Power Production with CO2 Capture Using Chemical-Looping ReformingRedox Reactivity of Particles of CuO, $\mathrm{Mn2O3}, \mathrm{NiO}$, and $\mathrm{Fe} 2 \mathrm{O} 3$ Using $\mathrm{SiO} 2$ as a Support. Industrial \& Engineering Chemistry Research, 2005. 44(10): p. 3485-3496. 
17. Rydén, M. and P. Ramos, $\mathrm{H} 2$ production with $\mathrm{CO} 2$ capture by sorption enhanced chemical-looping reforming using $\mathrm{NiO}$ as oxygen carrier and $\mathrm{CaO}$ as $\mathrm{CO} 2$ sorbent. Fuel Processing Technology, 2012. 96: p. 27-36.

18. Dou, B., et al., Hydrogen production by sorption-enhanced chemical looping steam reforming of ethanol in an alternating fixed-bed reactor: Sorbent to catalyst ratio dependencies. Energy Conversion and Management, 2018. 155: p. 243-252.

19. Zeng, L., et al., Iron oxide looping for natural gas conversion in a countercurrent moving bed reactor. Applied Energy, 2015. 157: p. 338-347.

20. Chen, S., et al., Hydrogen and electricity co-production plant integrating steam-iron process and chemical looping combustion. International Journal of Hydrogen Energy, 2012. 37(10): p. 8204-8216.

21. Kang, K.-S., et al., Oxygen-carrier selection and thermal analysis of the chemical-looping process for hydrogen production. International Journal of Hydrogen Energy, 2010. 35(22): p. 12246-12254.

22. Cormos, C.-C., Hydrogen production from fossil fuels with carbon capture and storage based on chemical looping systems. International Journal of Hydrogen Energy, 2011. 36(10): p. 5960-5971.

23. Edrisi, A., et al., Hydrogen, nitrogen and carbon dioxide production through chemical looping using iron-based oxygen carrier-A Green plant for $\mathrm{H} 2$ and N2 production. International Journal of Hydrogen Energy, 2014. 39(20): p. 10380-10391.

24. Zhang, X., et al., A hydrogen and oxygen combined cycle with chemical-looping combustion. Energy Conversion and Management, 2014. 85(C).

25. Khan, M.N. and T. Shamim, Techno-economic assessment of a plant based on a three reactor chemical looping reforming system. International Journal of Hydrogen Energy, 2016. 41(48): p. 22677-22688.

26. Cormos, C.-C., Biomass direct chemical looping for hydrogen and power co-production: Process configuration, simulation, thermal integration and techno-economic assessment. Fuel Processing Technology, 2015. 137: p. 16-23.

27. Gnanapragasam, N.V., B.V. Reddy, and M.A. Rosen, Hydrogen production from coal using coal direct chemical looping and syngas chemical looping combustion systems: Assessment of system operation and resource requirements. International Journal of Hydrogen Energy, 2009. 34(6): p. 2606-2615.

28. Yan, L., et al., Design and comparisons of three biomass based hydrogen generation systems with chemical looping process. International Journal of Hydrogen Energy, 2014. 39(31): p. 17540-17553.

29. Aziz, M., et al., Energy conservative brown coal conversion to hydrogen and power based on enhanced process integration: Integrated drying, coal direct chemical looping, combined cycle and hydrogenation. International Journal of Hydrogen Energy, 2017. 42(5): p. 2904-2913.

30. Darmawan, A., et al., Energy-efficient recovery of black liquor through gasification and syngas chemical looping. Applied Energy, 2018. 219: p. 290-298.

31. He, F., N. Galinsky, and F. Li, Chemical looping gasification of solid fuels using bimetallic oxygen carrier particles - Feasibility assessment and process simulations. International Journal of Hydrogen Energy, 2013. 38(19): p. 7839-7854.

32. Heng, L., H. Zhang, and R. Xiao, Hydrogen production from heavy fraction of bio-oil using iron-based chemical looping process: Thermodynamic simulation and performance analysis. International Journal of Hydrogen Energy, 2016. 41(40): p. 17771-17783. 
33. Johansson, M., T. Mattisson, and A. Lyngfelt, Comparison of oxygen carriers for chemical-looping combustion. Thermal Science, 2006. 10(3): p. 93-107.

34. Kang, K.-S., et al., Reduction and oxidation properties of Fe2O3/ZrO2 oxygen carrier for hydrogen production. Chemical Engineering Research and Design, 2014. 92(11): p. 25842597.

35. Zafar, Q., T. Mattisson, and B. Gevert, Redox investigation of some oxides of transitionstate metals $\mathrm{Ni}, \mathrm{Cu}, \mathrm{Fe}$, and supported on SiO 2 and $\mathrm{MgAl} 2 \mathrm{O}$ 4. Energy and Fuels, 2006. 20(1): p. 34-44.

36. Abad, A., et al., Mapping of the range of operational conditions for $\mathrm{Cu}$-, $\mathrm{Fe}$-, and $\mathrm{Ni}$ based oxygen carriers in chemical-looping combustion. Chemical Engineering Science, 2007. 62(1): p. 533-549.

37. Adekoya, T., Optimal Design of Heat Integration Strategies for Hydrogen Production, in Chemical Engineering. 2015, Imperial College London: London.

38. Douglas, J.M., Conceptual design of chemical processes. International ed. 2008, New York

London: McGraw-Hill.

39. Adminstration, U.E.I., International Energy Outlook 2016 with Projections to 2040. 2016, US Department of Energy: Washington.

40. Smith, J.M., Introduction to chemical engineering thermodynamics. 5th ed, ed. M.M. Abbott and H.C. Van Ness. 1996, New York

London: McGraw-Hill.

41. Peters, M.S., Plant design and economics for chemical engineers. 5th ed, ed. K.D. Timmerhaus and R. West. 2003, Boston

London: McGraw-Hill.

42. Couper, J.R., et al., Chemical Process Equipment: Selection and Design. 2013.

43. Garrett, D.E., Chemical Engineering Economics. 1989.

44. Fogler, H.S., Elements of chemical reaction engineering. Pearson international, 4th ed. 2006, Upper Saddle River, N.J.: Pearson Education International.

45. Kang, K.-S., et al., Modeling a counter-current moving bed for fuel and steam reactors in the TRCL process. International Journal of Hydrogen Energy, 2011. 37(4).

46. Levenspiel, O., Chemical reaction engineering. 3rd ed. 1999, New York

Chichester: Wiley.

47. Sinnott, R.K., Chemical engineering design. 4th ed, ed. J.M. Coulson and J.F. Richardson. 2005, Oxford: Elsevier Butterworth-Heinemann.

48. Survey, U.G., Mineral Commodities Suymmaries. 2016: Washington DC: United States.

49. Department for Buiseness, E.a.I.S., Industrial electricity prices in the IEA. 2016: UK.

50. Limited, T.W.U., Charges Schedule For the Supply of Water and Wastewater Services. 2017.

51. Abad, A., et al., Mapping of the range of operational conditions for $\mathrm{Cu}$-, $\mathrm{Fe}$-, and $\mathrm{Ni}$ based oxygen carriers in chemical-looping combustion. Chemical Engineering Science, 2007. 62(1): p. 533-549. 


\section{Appendices:}

A.1: Supplementary Figures 


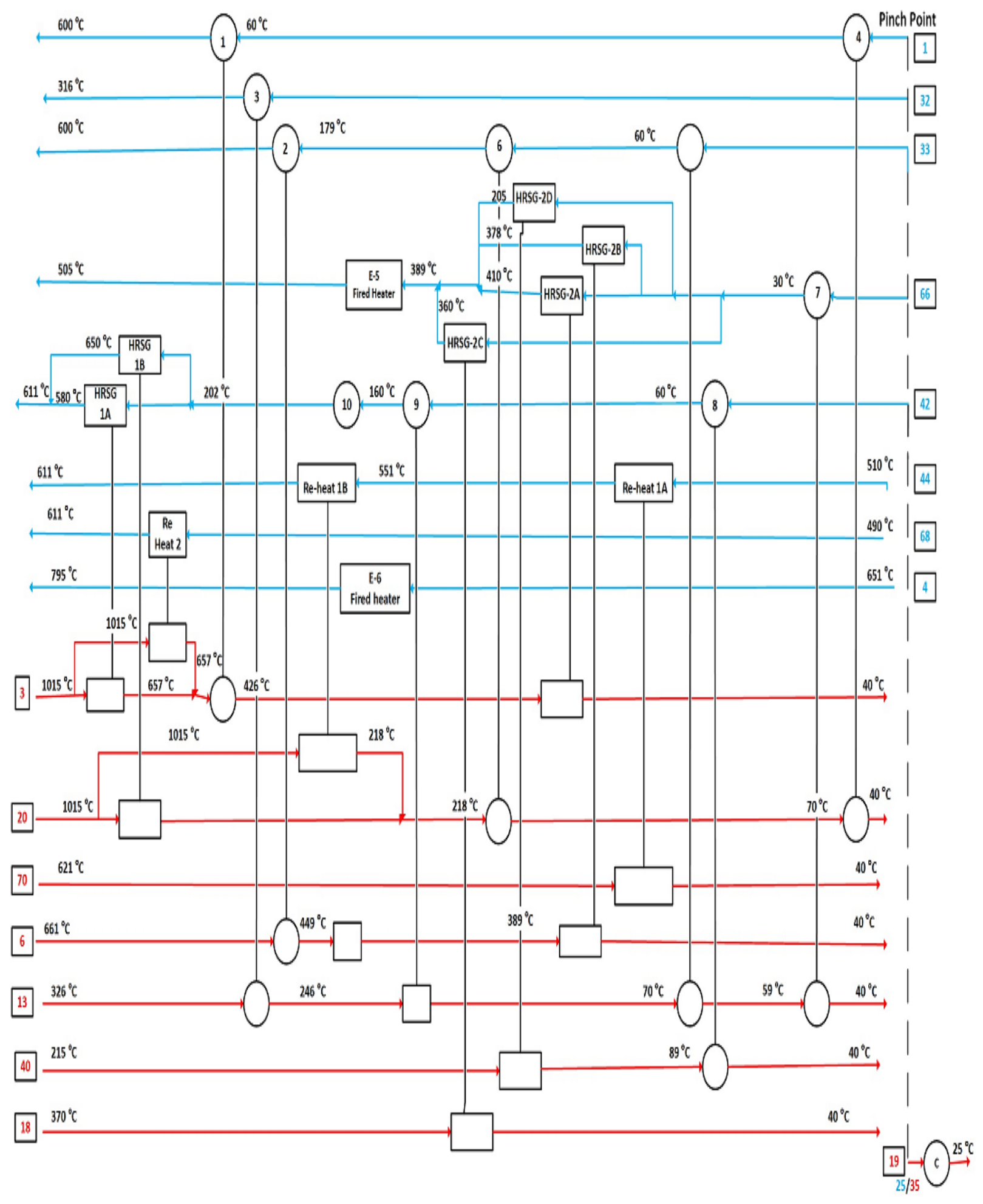

Fig. A1: The heat exchanger network for the ICLWS Process 


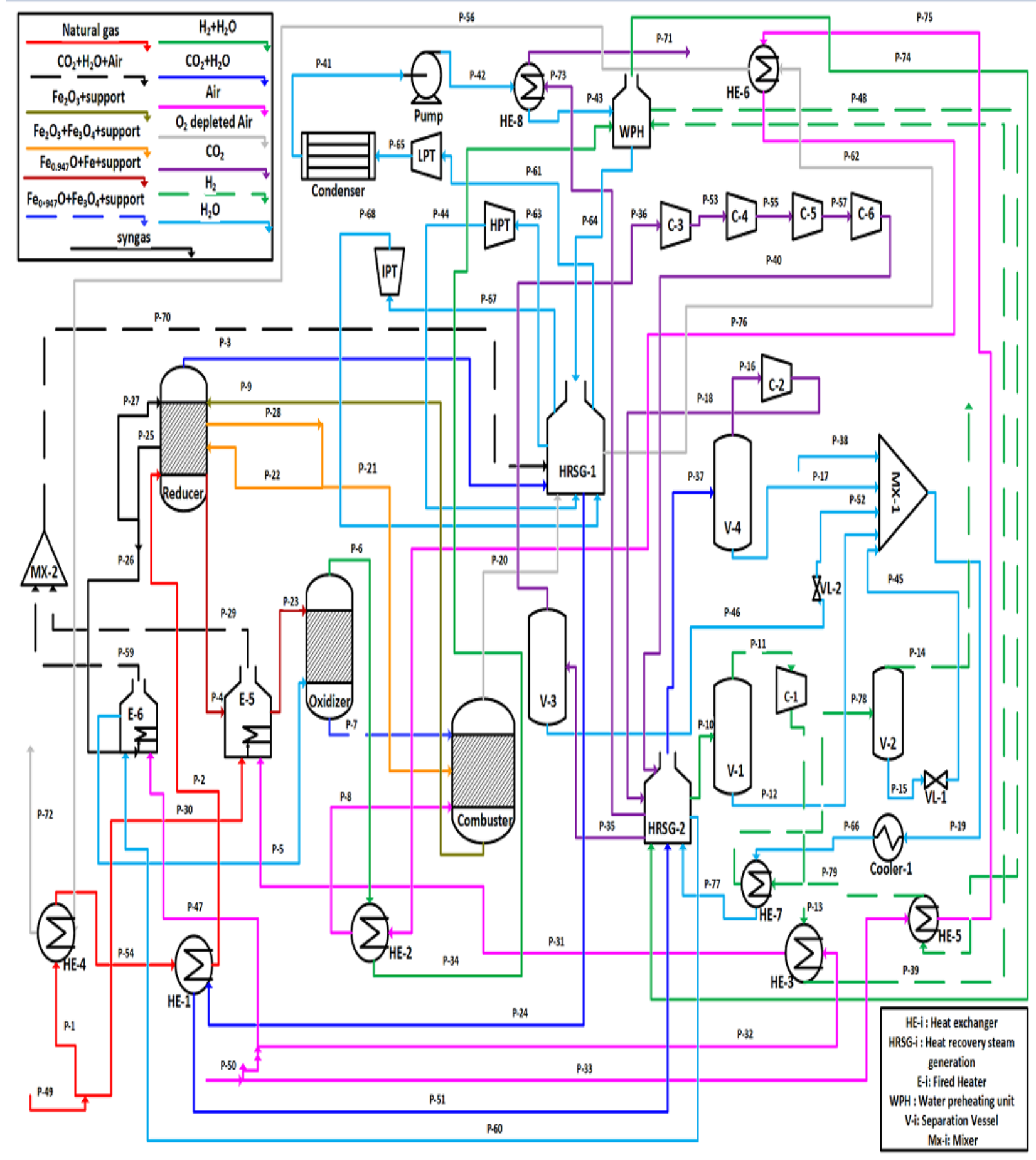

Fig. A2: The process flow diagram of the ICLWS process 


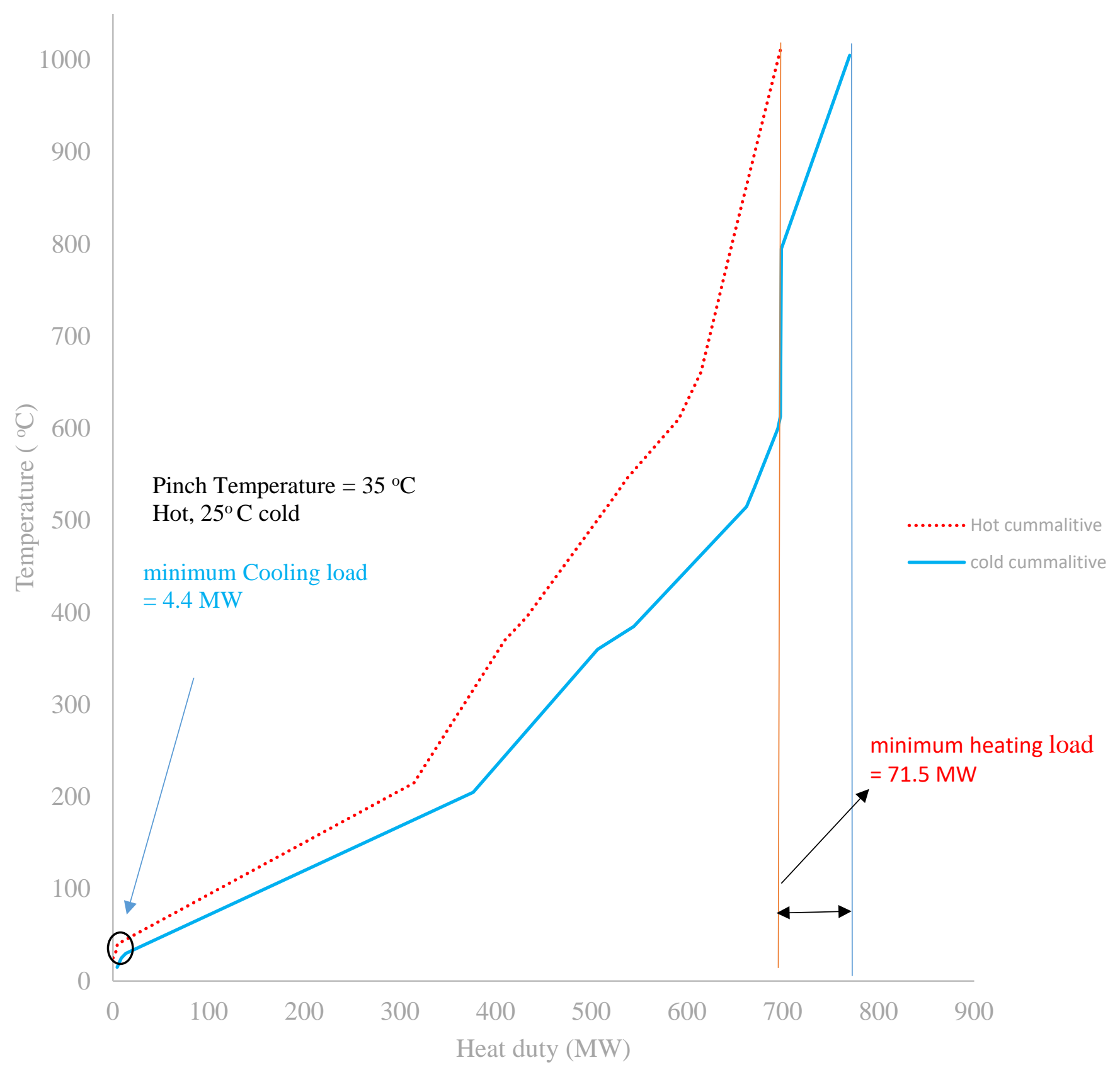

Fig. A3: Cumulative curves for the heat integration analysis performed on the BCLWS process 


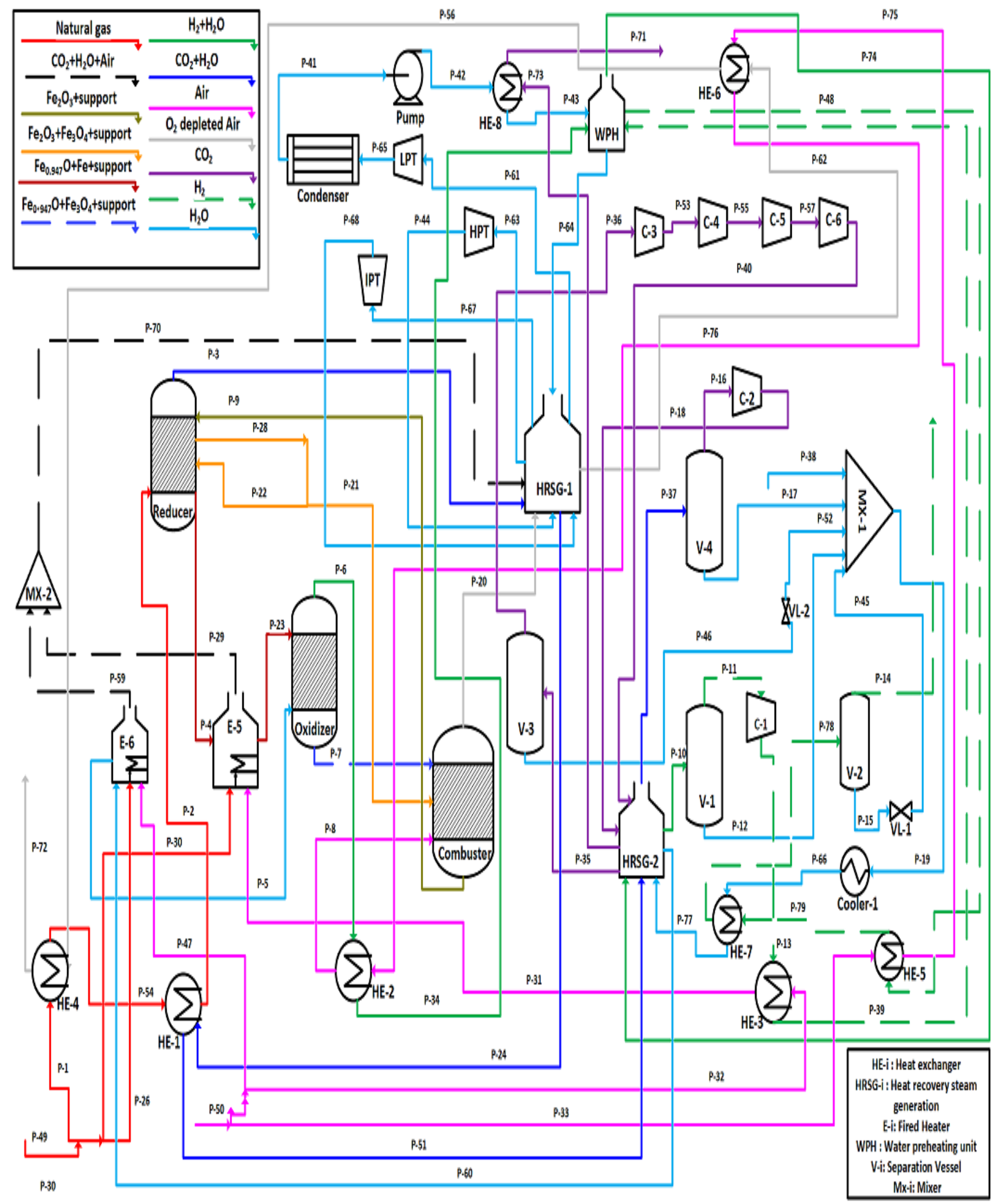

Fig.A4: Process flow diagram for the ICLWS(a) process 


\section{A.2: Energy Balance Tables}

Table A.1: Energy balance for the main units involved in the ICLWSIC process (a)

\begin{tabular}{|c|c|c|c|c|c|c|c|c|}
\hline $\begin{array}{l}\text { Equipment } \\
\text { symbol }\end{array}$ & Identification & $\begin{array}{c}\text { Streams } \\
\text { In }\end{array}$ & $\begin{array}{c}\text { Streams } \\
\text { out }\end{array}$ & $\mathrm{T}_{\text {in }}\left({ }^{\circ} \mathrm{C}\right)$ & $\begin{array}{l}\mathrm{T}_{\text {out }} \\
\left({ }^{\circ} \mathrm{C}\right)\end{array}$ & $\begin{array}{c}\mathbf{P}_{\text {in }} \\
\text { (bar) }\end{array}$ & $\begin{array}{l}\text { Pout } \\
\text { (bar) }\end{array}$ & $\begin{array}{c}\text { Energy } \\
\text { Associated } \\
\text { (MW) }\end{array}$ \\
\hline \multirow{2}{*}{ R1 } & \multirow{2}{*}{ Reducer } & 2 & 3 & 600 & 1015 & 1.0 & \multirow{2}{*}{1.2} & \multirow{2}{*}{103.7} \\
\hline & & 9 & 4 & 1015 & 651 & 1.2 & & \\
\hline \multirow{2}{*}{ R2 } & \multirow{2}{*}{ Oxidiser } & 23 & 7 & 805 & 820 & 1.2 & \multirow{2}{*}{1.2} & \multirow{2}{*}{-43.7} \\
\hline & & 5 & 6 & 505 & 656 & 1.2 & & \\
\hline \multirow{3}{*}{ R3 } & \multirow{3}{*}{ Combustor } & 7 & \multirow{2}{*}{20} & 820 & \multirow{2}{*}{1015} & 1.2 & \multirow{3}{*}{1.2} & \multirow{3}{*}{-60.4} \\
\hline & & 8 & & 600 & & 1.2 & & \\
\hline & & 21 & 9 & 1015 & 1015 & 1.2 & & \\
\hline \multirow{2}{*}{ HE-1 } & \multirow{2}{*}{$\begin{array}{c}\text { Heat } \\
\text { exchanger }\end{array}$} & 24 & 51 & 657 & 426 & 1.0 & 1.0 & \multirow{2}{*}{34.9} \\
\hline & & 54 & 2 & 55 & 600 & 1.2 & 1.2 & \\
\hline \multirow{2}{*}{ HE-2 } & \multirow{2}{*}{$\begin{array}{c}\text { Heat } \\
\text { exchanger }\end{array}$} & 6 & 34 & 661 & 449 & 1.2 & 1.2 & \multirow{2}{*}{38.3} \\
\hline & & 76 & 8 & 179 & 600 & 1.0 & 1.0 & \\
\hline \multirow{2}{*}{ HE-3 } & \multirow{2}{*}{$\begin{array}{c}\text { Heat } \\
\text { exchanger }\end{array}$} & 32 & 31 & 25 & 316 & 1.0 & 1.0 & \multirow{2}{*}{9.0} \\
\hline & & 13 & 39 & 326 & 246 & 10.0 & 10.0 & \\
\hline \multirow{2}{*}{ HE-4 } & \multirow{2}{*}{$\begin{array}{c}\text { Heat } \\
\text { exchanger }\end{array}$} & 1 & 54 & 25 & 60 & 1.0 & 1.0 & \multirow{2}{*}{1.5} \\
\hline & & 56 & 72 & 70 & 40 & 1.2 & 1.2 & \\
\hline \multirow{2}{*}{ HE-5 } & \multirow{2}{*}{$\begin{array}{c}\text { Heat } \\
\text { exchanger }\end{array}$} & 48 & 79 & 71 & 59 & 10.0 & 10.0 & \multirow{2}{*}{3.1} \\
\hline & & 33 & 75 & 25 & 61 & 1.0 & 1.0 & \\
\hline \multirow{2}{*}{ HE-6 } & \multirow{2}{*}{$\begin{array}{c}\text { Heat } \\
\text { exchanger }\end{array}$} & 75 & 76 & 60 & 179 & 1.0 & 1.0 & 102 \\
\hline & & 62 & 56 & 218 & 70 & 1.2 & 1.2 & 10.2 \\
\hline $\mathrm{HE}_{-7}$ & Heat & 79 & 78 & 59 & 40 & 10.0 & 10.0 & 32 \\
\hline ПЕ-न & exchanger & 66 & 77 & 25 & 30 & 1.2 & 1.2 & 3.2 \\
\hline & Heat & 73 & 71 & 89 & 40 & 110 & 110 & 78 \\
\hline HE-8 & Exchanger & 42 & 43 & 27 & 60 & 260 & 260 & 7.8 \\
\hline
\end{tabular}


Table A.2: Energy balance for the main units involved in the ICLWSIC process (b)

\begin{tabular}{|c|c|c|c|c|c|c|c|c|c|}
\hline $\begin{array}{l}\text { Equipment } \\
\text { symbol }\end{array}$ & Identification & $\begin{array}{l}\text { Streams } \\
\text { In }\end{array}$ & $\begin{array}{l}\text { Streams } \\
\text { out }\end{array}$ & $\mathbf{T}_{\text {in }}\left({ }^{\circ} \mathrm{C}\right)$ & $\begin{array}{l}\mathbf{T}_{\text {out }} \\
\left({ }^{\circ} \mathrm{C}\right)\end{array}$ & $\begin{array}{c}\mathbf{P}_{\text {in }} \\
\text { (bar) }\end{array}$ & $\begin{array}{c}\text { Pout } \\
\text { (bar) }\end{array}$ & \multicolumn{2}{|c|}{$\begin{array}{l}\text { Energy } \\
\text { Associated } \\
\text { (MW) }\end{array}$} \\
\hline \multirow{5}{*}{$\begin{array}{l}\text { HRSG-1 } \\
\text { (A-B) }\end{array}$} & \multirow{5}{*}{$\begin{array}{c}\text { Heat recovery } \\
\text { steam } \\
\text { generation }\end{array}$} & 64 & 63 & 208 & 612 & 260 & 260 & Total & 136.1 \\
\hline & & 3 & 24 & 1015 & 657 & 1.2 & 1.2 & A & 42.1 \\
\hline & & 20 & 62 & 1015 & 218 & 1.2 & 1.2 & B & 51.8 \\
\hline & & 44 & 67 & 510 & 612 & 150 & 150 & Reheat1 & 14 \\
\hline & & 68 & 61 & 480 & 612 & 70 & 70 & Reheat2 & 16.5 \\
\hline \multirow{3}{*}{$\begin{array}{l}\text { WPH (A- } \\
\text { B) }\end{array}$} & \multirow{3}{*}{$\begin{array}{c}\text { Water Pre- } \\
\text { Heating }\end{array}$} & 39 & 48 & 246 & 70 & 10 & 10 & A & 23.4 \\
\hline & & 34 & 74 & 461 & 389 & 1.2 & 1.2 & B & 12.7 \\
\hline & & 58 & 64 & 55 & 215 & 260 & 260 & \multicolumn{2}{|c|}{36.1} \\
\hline Condenser & Condenser & 65 & 41 & 25 & 25 & 0.026 & 0.026 & \multicolumn{2}{|c|}{-119.7} \\
\hline Cooler-1 & Cooler & 19 & 66 & 35 & 25 & 1.2 & 1.2 & \multicolumn{2}{|c|}{-4.4} \\
\hline \multirow{3}{*}{ E-5 } & \multirow{3}{*}{$\begin{array}{l}\text { Indirect fired } \\
\text { heater } \\
\text { (Combustion } \\
\text { heating) }\end{array}$} & 4 & 23 & 651 & 795 & 1.2 & 1.2 & \multirow{3}{*}{\multicolumn{2}{|c|}{71.5}} \\
\hline & & 30 & \multirow{2}{*}{29} & 25 & \multirow{2}{*}{661} & \multirow{2}{*}{1.0} & \multirow{2}{*}{1.0} & & \\
\hline & & 31 & & 360 & & & & & \\
\hline \multirow{3}{*}{ E-6 } & \multirow{3}{*}{ Fired heater } & 26 & 50 & 651 & $5 c 0$ & 1.2 & \multirow{3}{*}{1.2} & \multirow{3}{*}{\multicolumn{2}{|c|}{24.1}} \\
\hline & & 47 & & 25 & 300 & 1.0 & & & \\
\hline & & 60 & 5 & 395 & 505 & 1.2 & & & \\
\hline \multirow{2}{*}{ V-1 } & \multirow{2}{*}{$\begin{array}{l}\text { Separation } \\
\text { vessel }\end{array}$} & \multirow{2}{*}{10} & 11 & \multirow{2}{*}{40} & \multirow{2}{*}{40} & \multirow{2}{*}{1.2} & \multirow{2}{*}{1.2} & \multirow{2}{*}{\multicolumn{2}{|c|}{0.0}} \\
\hline & & & 12 & & & & & & \\
\hline \multirow{2}{*}{ V-2 } & \multirow{2}{*}{$\begin{array}{l}\text { Separation } \\
\text { vessel }\end{array}$} & \multirow{2}{*}{78} & 14 & \multirow{2}{*}{40} & \multirow{2}{*}{40} & 100 & 100 & 0 & \\
\hline & & & 15 & & & 10.0 & 10.0 & 0.1 & \\
\hline $\mathrm{V}-3$ & Separation & 35 & 36 & 40 & 40 & 212 & 212 & 0 & \\
\hline & vessel & & 46 & & & & & & \\
\hline $\mathrm{V}-4$ & Separation & 37 & 16 & 10 & 10 & 12 & 12 & 0 & \\
\hline$\sqrt{-4}$ & vesset & Jו & 17 & 40 & 40 & 1.2 & 1.2 & 0. & \\
\hline
\end{tabular}


Table A.3: Energy balance for the main units involved in the ICLWSIC process (c)

\begin{tabular}{|c|c|c|c|c|c|c|c|c|}
\hline $\begin{array}{l}\text { Equipment } \\
\text { symbol }\end{array}$ & Identification & $\begin{array}{l}\text { Streams } \\
\text { In }\end{array}$ & $\begin{array}{c}\text { Streams } \\
\text { out }\end{array}$ & $\mathbf{T}_{\text {in }}\left({ }^{\circ} \mathrm{C}\right)$ & $\begin{array}{l}\mathrm{T}_{\text {out }} \\
\left({ }^{\circ} \mathrm{C}\right)\end{array}$ & $\begin{array}{c}P_{\text {in }} \\
\text { (bar) }\end{array}$ & $\begin{array}{l}\text { Pout }_{\text {our) }} \\
\text { (bar) }\end{array}$ & $\begin{array}{c}\text { Energy } \\
\text { Associated } \\
\text { (MW) }\end{array}$ \\
\hline \multirow{5}{*}{ MX-1 } & \multirow{5}{*}{ Mixer } & 38 & \multirow{5}{*}{19} & 20 & \multirow{5}{*}{35} & \multirow{5}{*}{1.2} & \multirow{5}{*}{1.2} & \multirow{5}{*}{0.0} \\
\hline & & 17 & & 40 & & & & \\
\hline & & 52 & & 40 & & & & \\
\hline & & 12 & & 40 & & & & \\
\hline & & 45 & & 40 & & & & \\
\hline \multirow{2}{*}{ MX-2 } & \multirow{2}{*}{ Mixer } & 29 & \multirow{2}{*}{70} & 661 & \multirow{2}{*}{622} & \multirow{2}{*}{1.2} & \multirow{2}{*}{1.2} & \multirow{2}{*}{0.0} \\
\hline & & 59 & & 560 & & & & \\
\hline C-1 & Compressor & 11 & 13 & 40 & 396 & 1.2 & 10.0 & 31.8 \\
\hline $\mathrm{C}-2$ & Compressor & 16 & 18 & 40 & 370 & 1.2 & 21.2 & 16.9 \\
\hline C-3 & Compressor & 36 & 53 & 40 & 107 & 21.2 & 41.2 & 2.9 \\
\hline C-4 & Compressor & 54 & 55 & 40 & 68 & 41.2 & 61.2 & 2.7 \\
\hline $\mathrm{C}-5$ & Compressor & 56 & 57 & 40 & 55 & 61.2 & 81.2 & 1.7 \\
\hline C-6 & Compressor & 58 & 40 & 30 & 36 & 81.2 & 101.2 & 1.1 \\
\hline HPT & Turbine & 63 & 44 & 612 & 510 & 260 & 150 & -8.0 \\
\hline IPT & Turbine & 67 & 68 & 612 & 480 & 150 & 70 & -11.6 \\
\hline LPT & Turbine & 61 & 65 & 612 & 25 & 70 & 0.026 & -67.4 \\
\hline $\mathrm{P}-1$ & Pump & 41 & 42 & 25 & 27 & 1.0 & 260 & 1.6 \\
\hline VL-1 & Valve & 15 & 45 & 40 & 40 & 10.0 & 1.2 & 0.0 \\
\hline VL-2 & Valve & 46 & 52 & 40 & 40 & 21.2 & 1.2 & 0.0 \\
\hline
\end{tabular}

